\title{
Drought Assessment and Projection under Climate Change: A Case Study in the Middle and Lower Jinsha River Basin
}

\author{
Zhe Yuan, ${ }^{1}$ Jijun Xu, ${ }^{1}$ Jin Chen, ${ }^{1}$ Junjun Huo, ${ }^{1}$ Yangyue $Y u,{ }^{1}$ \\ Peter Locher, ${ }^{2}$ and Bin $\mathrm{Xu}^{1}$ \\ ${ }^{1}$ Changjiang River Scientific Research Institute, Wuhan, China \\ ${ }^{2}$ Ernst Basler + Partner, Zollikon, Switzerland \\ Correspondence should be addressed to Zhe Yuan; yuanzhe_0116@126.com
}

Received 4 February 2017; Accepted 18 April 2017; Published 30 May 2017

Academic Editor: Brian R. Nelson

Copyright (C) 2017 Zhe Yuan et al. This is an open access article distributed under the Creative Commons Attribution License, which permits unrestricted use, distribution, and reproduction in any medium, provided the original work is properly cited.

\begin{abstract}
To gain an insight into the spatiotemporal variability of drought events and to assess trends under future climate change scenarios are fundamental for making sound mitigation and adaptation strategies. A new drought index, standardized supply-demand water index (SSDI), has been proposed in this research. The SSDI describes drought from the view of water supply-demand relations using a simple water balance model. It was used to assess historical drought events in the middle and lower Jinsha river basin (MLJRB) located in the southwest China and applied to address the drought conditions in the MLJRB under current and future climates. The results showed the following: (1) The average drought area during 2001 to 2011 reached up to $9.9 \times 10^{3} \mathrm{~km}^{2}$, accounting for $35.4 \%$ of the whole farmland area in the MLJRB, which was about twice as the drought area during 1961 to 2000. The region for greater drought severity with more drought events and longer duration was mainly distributed in Dali, Chuxiong, Kunming, and Yuxi. (2) For the period 2021 to 2050 , total drought area was projected to increase by $43.2 \%$. The drought-prone regions could move further towards the northwest of the MLJRB.
\end{abstract}

\section{Introduction}

With the increasing impact of climate change, the frequency and severity of extreme weather events such as drought are increasing sharply, which have devastating effects on the fragile environment and human society [1]. The dry areas have increased by 1.5 times in the world since the 1970s [2]. More than 11 million deaths have been caused by drought disasters since the 1990s [3]. Located in East Asia, China has also been threatened by relentless droughts during the second half of twentieth century, which had negative influence on natural ecosystems and socioeconomic systems [4]. According to $\mathrm{Wu}$ and Gao [5], there are tens of millions of hectares of crops suffer from yield loss every year because of drought. In the context of climate change, China has witnessed higher frequency drought events in recent years, especially in southwest China. During the summer of 2006, Sichuan and Chongqing provinces endured their most severe drought since 1891. Over 16 million people and 17 million livestock lacked adequate drinking water. The drought also hit more than 2.5 million hectares of farmland, of which 0.75 million hectares of crops was demolished. It caused direct economic damage of US $\$ 3.5$ billion [6]. The autumn of 2009 to the spring of 2010 is another severe drought episode. The drink water for more than 16 million people and 11 million livestock cannot be ensured. Crops across more than 4 million hectares of farmland were devastated, leaving more than 1 million of them barren. The volume of most rivers shrank to $30-80 \%$ of their normal, and some dried up completely [7]. These severe droughts in southwest China were mainly led by less precipitation and warmer surface temperature [8].

These overwhelming drought conditions have been a particularly difficult challenge in China's management of natural disaster risks. Identifying the characteristics of drought can provide an understanding for the management of drought mitigation strategies $[9,10]$. Many previous literatures have investigated variations of drought events in China using different drought indices. There are many indices relative to 
drought, in which Palmer Drought Severity Index (PDSI) [11] and Standardized Precipitation Index (SPI) [12] are the two mostly used meteorological indices. But limitations still exist in the application of the abovementioned methods. For PDSI, data demand is relatively high. Field moisture capacity is needed as the input, which makes PDSI difficult to apply on larger scales [13]. According to the assessment report of the IPCC, the twentieth century has witnessed the rise of global surface temperatures by $0.74^{\circ} \mathrm{C}$. Under RCP 4.5 scenario, global surface temperature has been predicted to rise by $1.8^{\circ} \mathrm{C}$ (compared with that of 1986-2005) by the end of this century $[14,15]$. Therefore, indices including temperature data are preferable for analyzing the impacts of climate change on drought conditions. However, the SPI is based on precipitation only. It is not suitable for these types of applications. In addition, the newly developed Standardized Precipitation Evapotranspiration (SPEI) [16] combines the sensitivity of the PDSI to the changes in evapotranspiration with the simplicity of calculation but also has the robustness of the multitemporal nature of the SPI [17]. But this index cannot express the sensibility of crop to water deficit. It is a kind of metrological drought indices in essentially. Besides, many studies only focused on the observed trends or changes of drought [1719]. The future changes in drought under global warming are also important for agricultural adaptation and water resource management. In fact, the improvements in the CMIP5 dataset have given stronger foundation for research on the temporal and spatial changes of drought in the future [20].

Considering that the middle and lower Jinsha river basin (MLJRB) is one of the most important regions in China and it has been suffering from drought and related problems, this research did a case study in the MLJRB. In this study, we have described a drought index (the standardized supply-demand water index (SSDI)) that uses crop evapotranspiration and effective precipitation and it is based on a normalization of the simple water balance. For driving forces, the SSDI considers the influence of climate variability (e.g., precipitation, temperature) and underlying conditions (e.g., land use and type of crop). For water resources systems, the SSDI considered water supply and water demand during crop growth period. For basic data demand, only land use and meteorological data are needed. The main advantage of the SSDI lies in its capability to identify the agricultural drought and simple calculation procedure. Future, this research tried to identify the spatial and temporal variability of drought in the MLJRB over the recent decades and next several decades with the observed daily meteorological data and bias-corrected climate dataset from five general circulation models (GCMs) so as to provide beneficial reference to drought management and risk assessment.

\section{Materials and Methods}

2.1. Study Area. The Jinsha River Basin (JRB, $90^{\circ} 30^{\prime}-105^{\circ} 15^{\prime} \mathrm{E}$ and $24^{\circ} 36^{\prime}-35^{\circ} 44^{\prime} \mathrm{N}$ ) is located in southwest of China, covering an area of $474,520 \mathrm{~km}^{2}$ shared by 4 provinces and autonomous regions (namely, Qinghai, Tibet, Yunnan, and Sichuan) [21]. The Jinsha River, the upper reach of the Yangtze

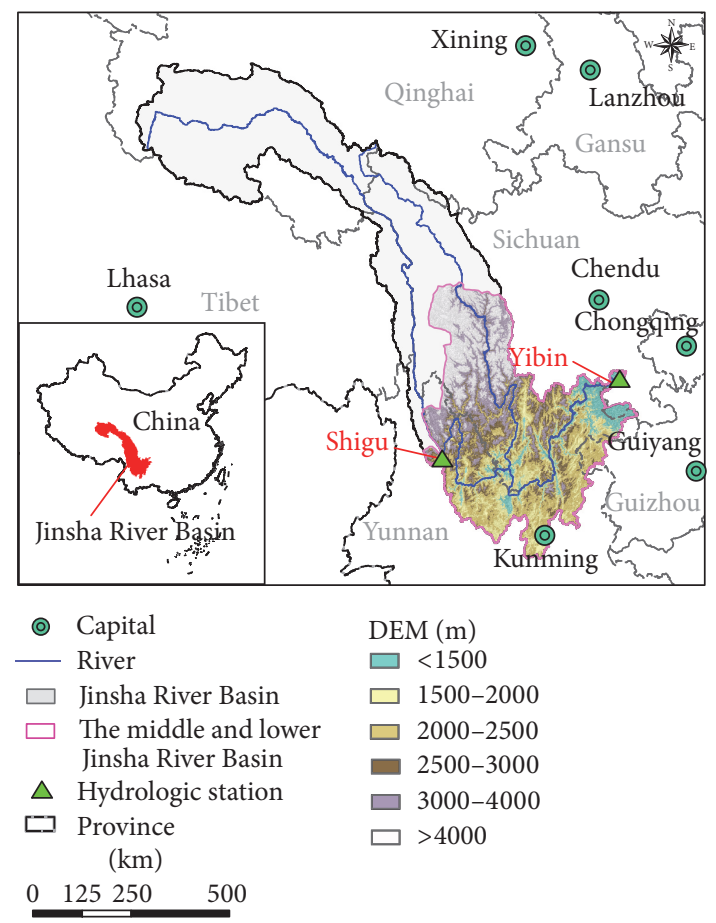

FIGURE 1: Comprehensive map of the study area.

River, is about $3464 \mathrm{~km}$ in length and passes through a range of landscapes, originating in Qinghai-Tibet Plateau, cutting through Western Sichuan Plateau, Hengduan Mountains and Yunnan-Guizhou Plateau to the mountain area of Southwest Sichuan [22] (Figure 1). The average annual temperature is $10.2^{\circ} \mathrm{C}$ in JRB [23]. The annual average precipitation in the upper, middle, and lower reaches is $350 \mathrm{~mm}, 600 \mathrm{~mm}$, and $1000 \mathrm{~mm}$, respectively [24]. Of the total annual precipitation, about $90 \%$ falls in the wet season (From May to October) [25]. The average annual runoff is about $152 \times 10^{6} \mathrm{~m}^{3}$, which mainly concentrates from July to September [22].

The JRB acts as an important water source in the west route of South-to-North Water Transfer Project. A total of $1.5 \times 10^{9} \mathrm{~m}^{3} /$ year of water is to be transferred from the upper reaches of the Yalong River to the northern part of China in the first phase [26]. The JRB also contributes to irrigation, water supply, flood control, wood drift, and tourism. Overall, the JRB plays a very important role in regional and national economic development.

The area of middle and lower Jinsha River Basin (the MLJRB, from Shigu to Yibin) is $213,102 \mathrm{~km}^{2}$, accounting approximately $45 \%$ of the JRB. The average annual temperature and precipitation are $9.1^{\circ} \mathrm{C}$ and $864.7 \mathrm{~mm}$, respectively. The MLJRB feeds $95.8 \%$ of the JRB population and $98.6 \%$ of the JRB Gross Domestic Product (GDP). About 96.8\% farmland is in middle and lower basin (Figure 2). That is, the MLJRB plays a very important role in economic development and agricultural production. However, with the increasing impact of climate change, droughts happen in this region with higher frequency. It caused huge damage to social economy and ecosystem in MLJRB [27-29]. 

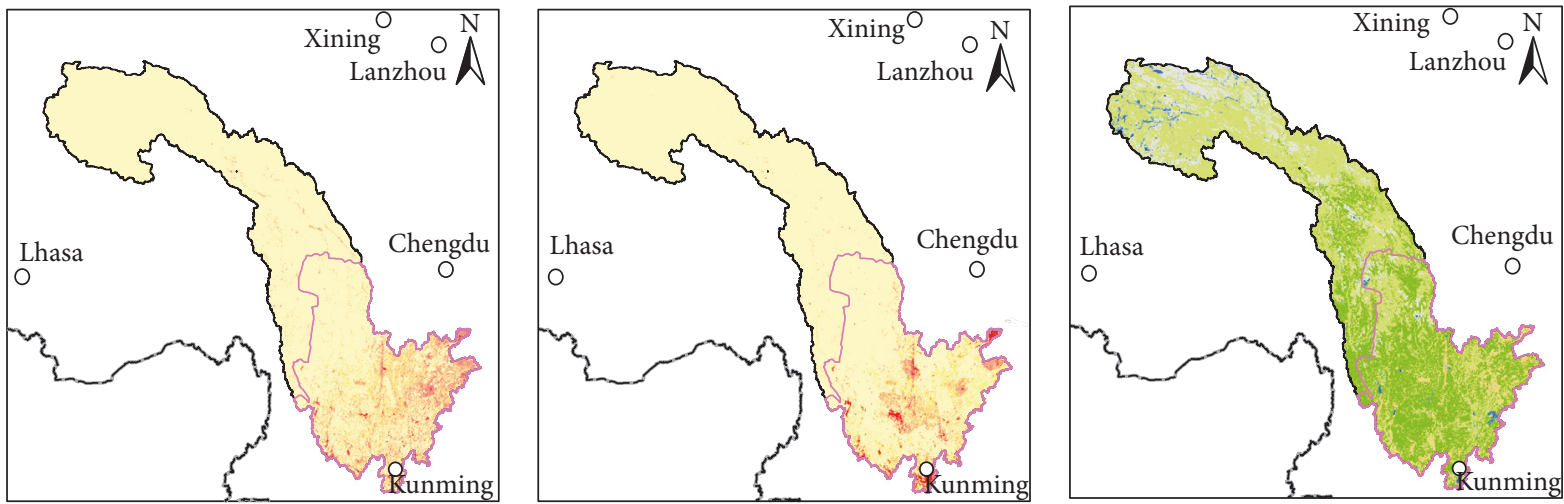

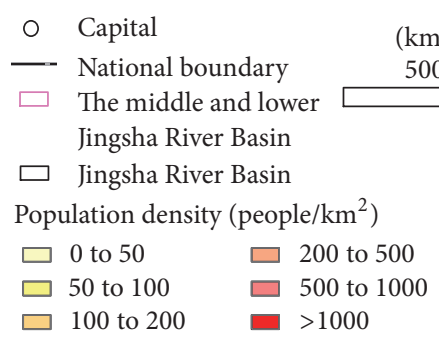

(a)

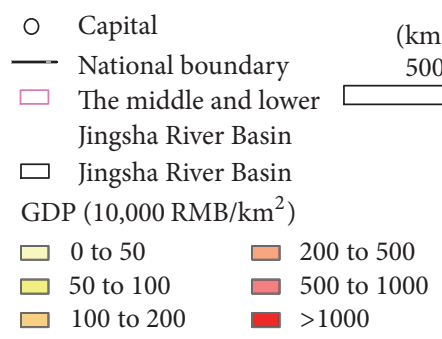

(b)

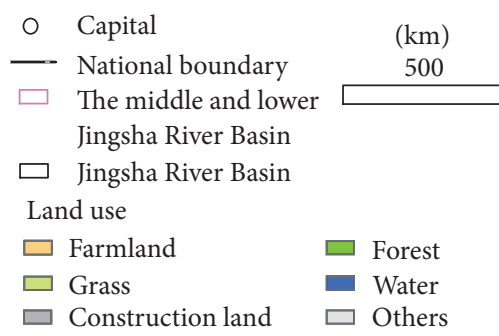

(c)

FIgURE 2: The population density, GDP, and land use in JRB (2010). The population density, GDP, and land use maps are obtained from the Data Center for Resources and Environmental Sciences (RESDC), Chinese Academy of Sciences (http://www.resdc.cn/).
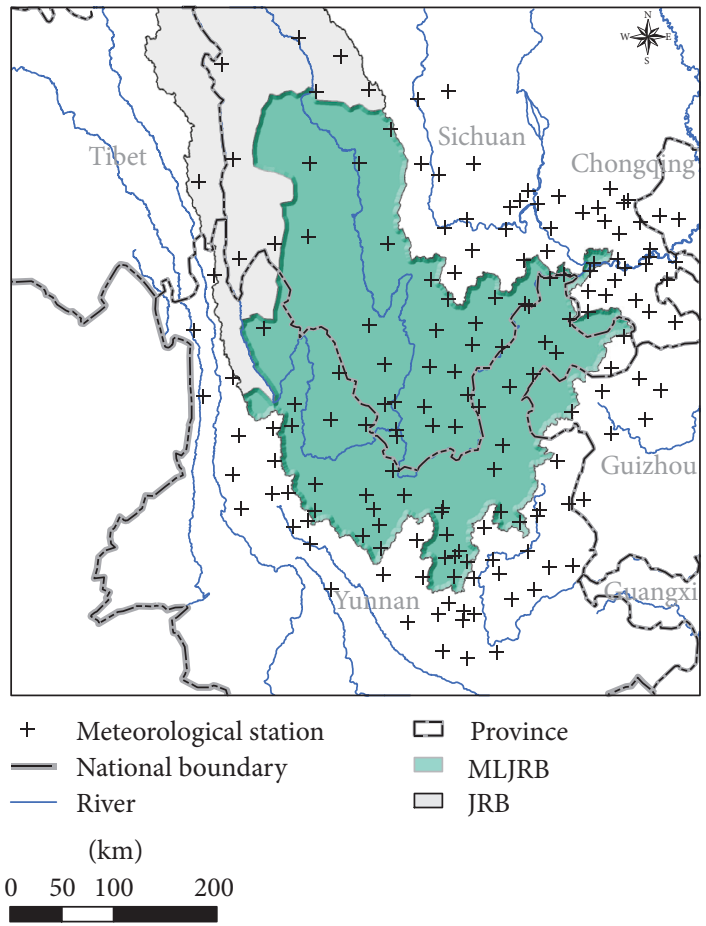

FIgURE 3: Meteorological stations used in MLJRB.

2.2. Data. Observed daily meteorological data from 165 meteorology stations in and around the MLJRB were collected for this study (Figure 3), 128 of them that have continuous data series from 1960 to 2013. There were more than 148

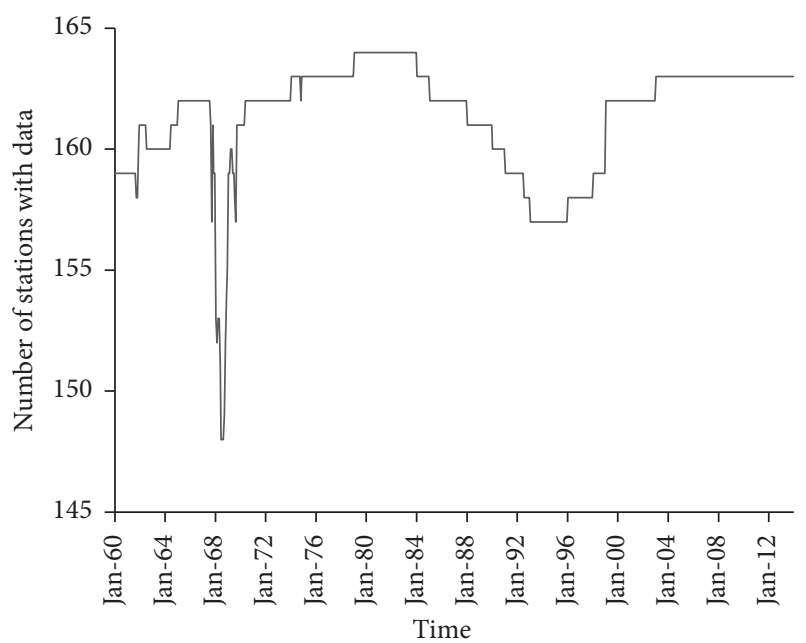

Figure 4: Number of stations with data (monthly).

stations that have data in each month (Figure 4). The dataset, including precipitation, highest temperature, lowest temperature, average temperature, sunshine hours, wind speed, and relative humidity, is provided by China Meteorological Data Sharing Service System (http://data.cma.cn/). Thin plate spline $[30,31]$ and the GTOPO30 (Global 30 arc-second elevation) $\mathrm{DEM}$ data were used to resample to generate the digital elevation model $\left(0.5^{\circ} \times 0.5^{\circ}\right)$, thus eliminating the impact of elevation on the spatial interpolation of each meteorological element. The interpolated dataset has the same resolution with the climate dataset. Thus, it can be used to evaluate the performance of the climate dataset. 
TABLE 1: List of general circulation models (GCMs) used in this study.

\begin{tabular}{lcc}
\hline Centre & Country & Name \\
\hline Geophysical Fluid Dynamics Laboratory (GFDL) & United States & GFDL-ESM2M \\
Hadley Centre for Climate Prediction and Research, Met Office & United Kingdom & HADGEM2-ES \\
L'Institut Pierre-Simon Laplace (IPSL) & France & IPSL-CM5A-LR \\
Technology, Atmosphere and Ocean Research Institute, and National & Japan & MIROC-ESM-CHEM \\
Institute for Environmental Studies & Norway & NORESM1-M \\
Norwegian Climate Centre & & N
\end{tabular}

Climate change scenarios for this case study are obtained from the Inter-Sectoral Impact Model Intercomparison Project (ISI-MIP, http://www.isi-mip.org). The ISI-MIP climate dataset includes five global climate models (GFDLESM2M, HadGEM2-ES, IPSL-CM5A-LR, MIROC-ESMCHEM, and NorESM1-M) and covers the period from 1960 to 2099 on a horizontal grid with $0.5^{\circ} \times 0.5^{\circ}$ resolution (Table 1 ) [35]. In order to guarantee long-term statistical consistency between projected data and observational data (1960-1999), data was bias-corrected. Projected absolute trends in temperature and relative trends in precipitation have been retained by bias-correction method [36, 37]. In this study, we used the midrange mitigation emissions scenario (RCP4.5) and the period 2011-2050. There were 130 grid boxes with daily precipitation, highest temperature, lowest temperature, average temperature, total solar radiation, wind speed, and relative humidity in and around the MLJRB (Figure 5).

\subsection{Calculation of Crop Evapotranspiration and Effective Precipitation}

2.3.1. Crop Evapotranspiration. Crop evapotranspiration can be obtained by indirect estimation methods, which is based on the reference evapotranspiration and crop coefficients. This kind of approach has advantage in estimating crop water demand at large scales due to its relative simplicity [38-40]. The crop evapotranspiration is simulated as

$$
\mathrm{ET}_{c}=K_{c} \times \mathrm{ET}_{0}
$$

where $\mathrm{ET}_{c}(\mathrm{~mm})$ is crop evapotranspiration, $K_{c}$ is the crop coefficient value in MLJRB as shown in Table 2, and $\mathrm{ET}_{0}$ $(\mathrm{mm})$ is the reference evapotranspiration which can be calculated by FAO Penman-Monteith method using daily meteorological data (Allen et al. 1994):

$$
\begin{aligned}
& \mathrm{ET}_{0} \\
& =\frac{0.408 \Delta\left(R_{n}-G\right)+\gamma(900 /(T+273)) u_{2}\left(e_{s}-e_{a}\right)}{\Delta+\gamma\left(1+0.34 \mu_{2}\right)}
\end{aligned}
$$

where $\mathrm{ET}_{0}$ is reference evapotranspiration ( $\left.\mathrm{mm} / \mathrm{day}\right) ; R_{n}$ is the net radiation at the crop surface $\left(\mathrm{MJ} /\left(\mathrm{m}^{2} \cdot\right.\right.$ day $\left.)\right) ; G$ is the soil heat flux density $\left(\mathrm{MJ} /\left(\mathrm{m}^{2} \cdot\right.\right.$ day $\left.)\right) ; T$ is the air temperature at $2 \mathrm{~m}$ height $\left({ }^{\circ} \mathrm{C}\right) ; u_{2}$ is the wind speed at $2 \mathrm{~m}$ height $(\mathrm{m} / \mathrm{s})$; $e_{s}$ is the saturation vapor pressure $(\mathrm{kPa}) ; e_{a}$ is the actual vapor pressure $(\mathrm{kPa}) ; \Delta$ is the slope of the saturation vapor pressure

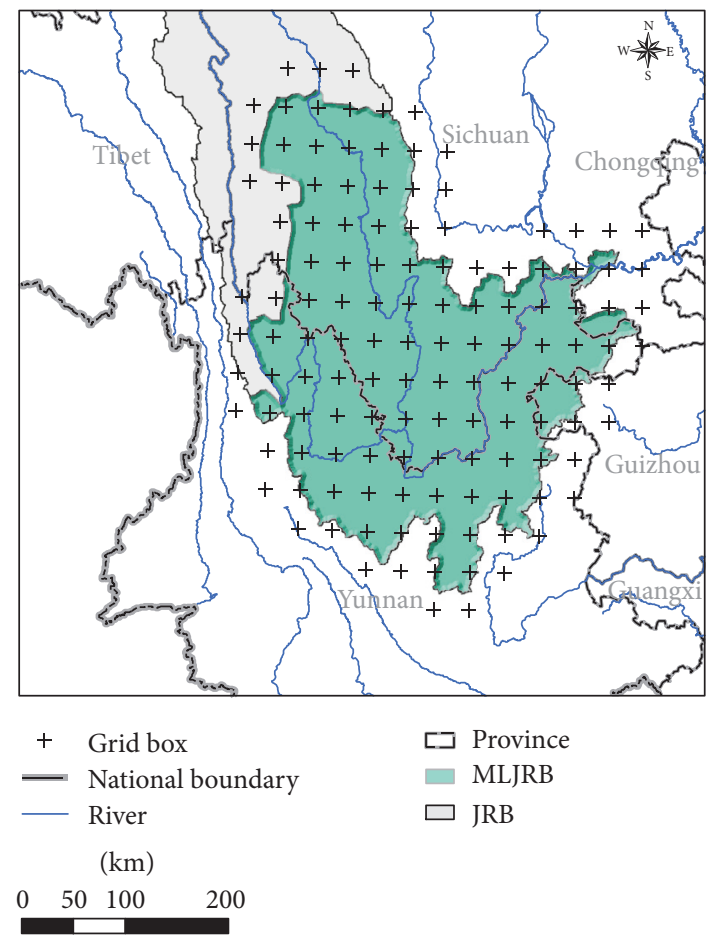

Figure 5: Grid boxes selected in MLJRB.

temperature curve $\left(\mathrm{kPa} /{ }^{\circ} \mathrm{C}\right)$; and $\gamma$ is the psychometric constant $\left(\mathrm{kPa} /{ }^{\circ} \mathrm{C}\right)$.

Warmer climate generally results in a shorter growth period and can affect the crop evapotranspiration indirectly (Mahmood 1997), which suggests that the effect of crop phenophase change should be accounted for. In this study, the dates of different growth stages were detected in by using the relationship between phenophase and accumulated temperature [41]. Based on the research performed by Lu and Wang [33], the accumulated temperature $\geq 10^{\circ} \mathrm{C}$ (AT10, (3)) was chosen as an indicator to identify the growth stage:

$$
\mathrm{AT} 10=\sum_{i=1}^{n} T_{i} \quad T_{i} \geq 10,
$$

where AT10 is the accumulated temperature $\geq 10^{\circ} \mathrm{C} ; n$ is the days within each growth stage; $T_{i}$ is the average temperature on day $i$. If $T_{i}<10, T_{i}=0$. All the days with average temperatures above $10^{\circ} \mathrm{C}$ were considered for calculation. The AT10 threshold of each stage is given in Table 3. 
TABLE 2: Crop coefficient in each growth stage [32].

\begin{tabular}{lcccc}
\hline \multicolumn{1}{c}{ Wheat } & \multicolumn{2}{c}{ Maize } & \multicolumn{2}{c}{ Rice } \\
Growth stage & $K_{c}$ & Growth stage & $K_{c}$ & Growth stage \\
\hline Sowing-emergence & 0.70 & Sowing-emergence & 0.40 & Sowing-reviving \\
Emergence-tillering & 0.40 & Emergence-silking & 1.18 & Reviving-tillering \\
Tillering-jointing & 0.75 & Silking-dough & 0.80 & Tillering-jointing \\
Jointing-heading & 1.10 & & & Jointing-heading \\
Heading-dough & 0.85 & & & Heading-dough \\
\hline
\end{tabular}

This study chooses wheat, maize, and rice as the major crops.

TABLE 3: AT10 thresholds of major crops at different growth stages [33, 34].

\begin{tabular}{lcccc}
\hline \multicolumn{1}{c}{ Wheat } & \multicolumn{2}{c}{ Maize } & \multicolumn{2}{c}{ Rice } \\
Growth stage & AT10 & Growth stage & AT10 & Growth stage \\
\hline Sowing-emergence & 134 & Sowing-emergence & 224 & Sowing-reviving \\
Emergence-tillering & 148 & Emergence-silking & 1500 & Reviving-tillering \\
Tillering-jointing & 179 & Silking-dough & 1324 & Tillering-jointing \\
Jointing-heading & 311 & & & Jointing-heading \\
Heading-dough & 686 & & & Heading-dough \\
\hline
\end{tabular}

Daily average temperature varying from 15 to $18^{\circ} \mathrm{C}$ is most suitable for wheat sowing. When the daily average temperature is within the abovementioned temperature range $\left(15 \sim 18^{\circ} \mathrm{C}\right)$ for five consecutive days, the first day of the period is defined as the sowing day of wheat. The suitable daily average temperature for maize and rice sowing varies from 12 to $15^{\circ} \mathrm{C}$ and 10 to $15^{\circ} \mathrm{C}$. In the same way, we can detect the day for maize and rice sowing.

2.3.2. Effective Precipitation. Effective precipitation is the fraction of the total precipitation. It is available to the crop and dose not runoff. Empirical formulas for the calculation of effective precipitation need detailed site-specific information (e.g., soil textures and crop). This kind of approach is complicated and is not universal. In this study, we used a simplified method given by the US Department of Agriculture Soil Conservation [42].

$$
P_{e}= \begin{cases}\frac{P(4.17-0.2 P)}{4.17} & (P<8.3 \mathrm{~mm} / \mathrm{d}) \\ 4.17+0.1 P & (P \geq 8.3 \mathrm{~mm} / \mathrm{d}),\end{cases}
$$

where $P$ is daily precipitation $(\mathrm{mm} / \mathrm{d}) ; P_{e}$ is effective precipitation $(\mathrm{mm} / \mathrm{d})$.

2.4. Standardized Supply-Demand Water Index. A simple multiscalar drought index, standard supply-demand water index (SSDI), has been proposed in this research. The SSDI combines effective precipitation and crop evapotranspiration. It is based on the original SPI or SPEI calculation procedure. The monthly difference between effective precipitation and crop evapotranspiration is used as the input data. This represents a simple climatic water balance that is calculated at different time scales to obtain the SSDI.

Using the method discussed in Section 2.4, we can obtain the daily crop evapotranspiration and effective precipitation.
With the value for $\mathrm{ET}_{c}$ and $P_{e}$, the difference between them for the month $i$ is calculated:

$$
D_{i}=P_{e i}-\mathrm{ET}_{c i}
$$

Equation (4) provides a simple measure of the water surplus $\left(D_{i}>0\right)$ or deficit $\left(D_{i}<0\right)$ for the month $i$. The calculated $D_{i}$ values are aggregated at different time scales (e.g., 1-month time scale, 3-month time scale, 6-month time scale, or 12-month time scale):

$$
D_{n}^{k}=\sum_{i=0}^{k-1}\left(P_{e_{n-1}}-\mathrm{ET}_{c_{n-1}}\right) \quad n \geq k
$$

where $k$ is the time scale; $n$ is the analyzed month.

According to the study of Vicente-Serrano et al. [16], we selected the log-logistic distribution for standardizing the $D$ series to calculate the SSDI. The probability distribution function (PDF) of the $D$ series according to a three-parameter loglogistic distribution is expressed as

$$
F(x)=\left[1+\left(\frac{\alpha}{x-\gamma}\right)^{\beta}\right]^{-1},
$$

where $\alpha, \beta$, and $\gamma$ are the scale, shape, and location parameters, respectively, which are estimated from $D$ series. This study used the $L$-moment procedure to obtain the parameters because this method was robust and easy [43].

$$
\begin{aligned}
& \beta=\frac{2 w_{1}-w_{0}}{6 w_{1}-w_{0}-6 w_{2}}, \\
& \alpha=\frac{\left(w_{0}-2 w_{1}\right) \beta}{\Gamma(1+1 / \beta) \Gamma(1-1 / \beta)}, \\
& \gamma=w_{0}-\alpha \Gamma\left(1+\frac{1}{\beta}\right) \Gamma\left(1-\frac{1}{\beta}\right),
\end{aligned}
$$


TABLE 4: Classification of the SSDI values and drought category.

\begin{tabular}{lc}
\hline SSDI & Drought category \\
\hline 0 to -0.99 & Near normal \\
-1.00 to -1.49 & Moderate drought \\
-1.50 to -1.99 & Severe drought \\
$\leq-2.00$ & Extreme drought \\
\hline
\end{tabular}

where $\Gamma(\beta)$ is the gamma function of $\beta ; w_{0}, w_{1}$, and $w_{2}$ are Probability Weighted Moments (PWMs) of different orders [44]; they can be calculated as

$$
w_{s}=\frac{1}{N} \sum_{i=1}^{N}\left(1-F_{i}\right)^{s} D_{i},
$$

where $s$ is the order of PWMs; $N$ is the number of data points; $F_{i}$ is a frequency estimator which can be obtained using the formula

$$
F_{i}=\frac{i-0.35}{N},
$$

where $i$ is the range of observations arranged in increasing order.

Using (8), (9), and (10), we can get the modeled $F(x)$. Then the SSDI can be obtained with the standardized $F(x)$ values:

$$
\begin{aligned}
& P=1-F(x), \\
& \text { if } P \leq 0.5 \quad W=\sqrt{-2 \ln (P)}, \\
& \text { SSDI }=W-\frac{c_{0}+c_{1} W+c_{2} W_{2}}{1-d_{1} W+d_{2} W_{2}+d_{3} W_{3}}, \\
& \text { else } \quad W=\sqrt{-2 \ln (1-P)}, \\
& \text { SSDI }=\frac{c_{0}+c_{1} W+c_{2} W_{2}}{1-d_{1} W+d_{2} W_{2}+d_{3} W_{3}}-W .
\end{aligned}
$$

The constants are $c_{0}=2.515517, c_{1}=0.802853, c_{2}=$ $0.010328, d_{1}=1.432788, d_{2}=0.189269$, and $d_{3}=0.001308$.

In this study the three-category drought classification is used according to Vermes [45]. The threshold of SSDI for drought severity class is listed as in Table 4.

Above all, the overall procedure for drought assessment based on SSDI can be described as Figure 6 .

\subsection{Analysis of Drought Characteristics by the Theory of Runs.} To assess the variability and pattern of the drought characteristics, the value of the drought times (DT), drought duration (DD), and drought severity (DS) were computed for every grid during a given period. DT, DD, and DS were calculated by theory of runs [46]. The DD was expressed in 1 month during which a drought parameter is continuously below the critical level. Namely, it was the time period between the initiation and termination of a drought event. The DS indicated a cumulative deficiency of a drought parameter below the critical level. In this study, $X_{0}$ and $X_{1}$ were the threshold level of the SSDI. They were 0.00 and -1.00 , respectively.
Figure 7 showed that " $a$ ", " $b$," and " $c$ " were drought events because the SSDI were less than $X_{1}$. There was one unit of the SSDI above $X_{1}$ but below $X_{0}$ between " $b$ " and " $c$," so we consider " $b$ " and " $c$ " as one drought event. More details can be found in the studies by Lu et al. [47].

2.6. Selection of Relative Optimal GCMs. This study uses the correlation coefficient of the linear regression equation $\left(R^{2}\right)$ to assess the GCMs' feasibility in the study area. The calculation formulas are as follows:

$$
R^{2}=\frac{\left[\sum_{i=1}^{n}\left(X_{\mathrm{sim}-i}-\overline{X_{\mathrm{sim}}}\right)^{2} \sum_{i=1}^{n}\left(X_{\mathrm{obs}-i}-\overline{X_{\mathrm{obs}}}\right)\right]^{2}}{\sum_{i=1}^{n}\left(X_{\mathrm{obs}-i}-\overline{X_{\mathrm{obs}}}\right)^{2} \sum_{i=1}^{n}\left(X_{\mathrm{sim}-i}-\overline{X_{\mathrm{sim}}}\right)^{2}},
$$

where $X_{\text {obs- } i}$ is observed crop evapotranspiration or effective precipitation $(\mathrm{mm})$ and $R_{\text {sim- } i}$ is simulated value by GCMs. $\overline{X_{\mathrm{obs}}}$ and $\overline{X_{\text {sim }}}$ are the means of observed and simulated values, respectively (mm), and $n$ is the number of observed values. Models perform better with higher $R^{2}$. This research assumes that the GCM with the highest $R^{2}$ is the relative optimal model and projects future changes in drought with the output of the relative optimal model.

\section{Results}

3.1. Crop Evapotranspiration and Effective Precipitation in the $M L J R B$. Figures $8(\mathrm{a})$ and $8(\mathrm{~b})$ show the time series of crop evapotranspiration and effective precipitation. Figures 9(a) and 9 (b) show the distribution of slope across the MLJRB during 1961 to 2011. The mean annual crop evapotranspiration in the MLJRB over the period 1961 to 2011 is $971.8 \mathrm{~mm}$. It could be found that there was a negative trend in the MLJRB during the last 50 years with the average annual decreasing rate of $1.66 \mathrm{~mm} / 10 \mathrm{a}$. But the trend did not pass the significance test through Mann-Kendall test (Figure 8(a)). From the perspective of spatial variety, crop evapotranspiration in the area of Yibin, Panzhihua, Kunming, and Yuxi showed a decreasing trend, while it has been increased in Zhongdian, Xichang, and Lijiang (Figure 9(a)). The climate of the MLJRB has become drier during the last 50 years. The effective precipitation has decreased by $8.1 \mathrm{~mm}$ per decade from 1961 to 2011 and the negative trend has been statistical significant at $\alpha=0.01$ level (Figure 8(b)). The break points of the annual effective precipitation tested by the Mann-Kendall method were in the beginning of the 1970s and the late of the 1990s. Annual effective precipitation during 2001 to 2011 was $429.0 \mathrm{~mm}$, which has decreased by $8.3 \%$ and $6.8 \%$ compared with the average value during 1961 to $1970(467.8 \mathrm{~mm})$ and 1971 to 2000 $(460.0 \mathrm{~mm})$. The decreasing extent of effective precipitation is comparatively big in the east of the MLJRB, especially in the Yibin, Liupanshui, Dongchuan, and Qujing where the increasing extent is more than $15 \mathrm{~mm} / 10$ a (Figure $9(\mathrm{~b})$ ). 


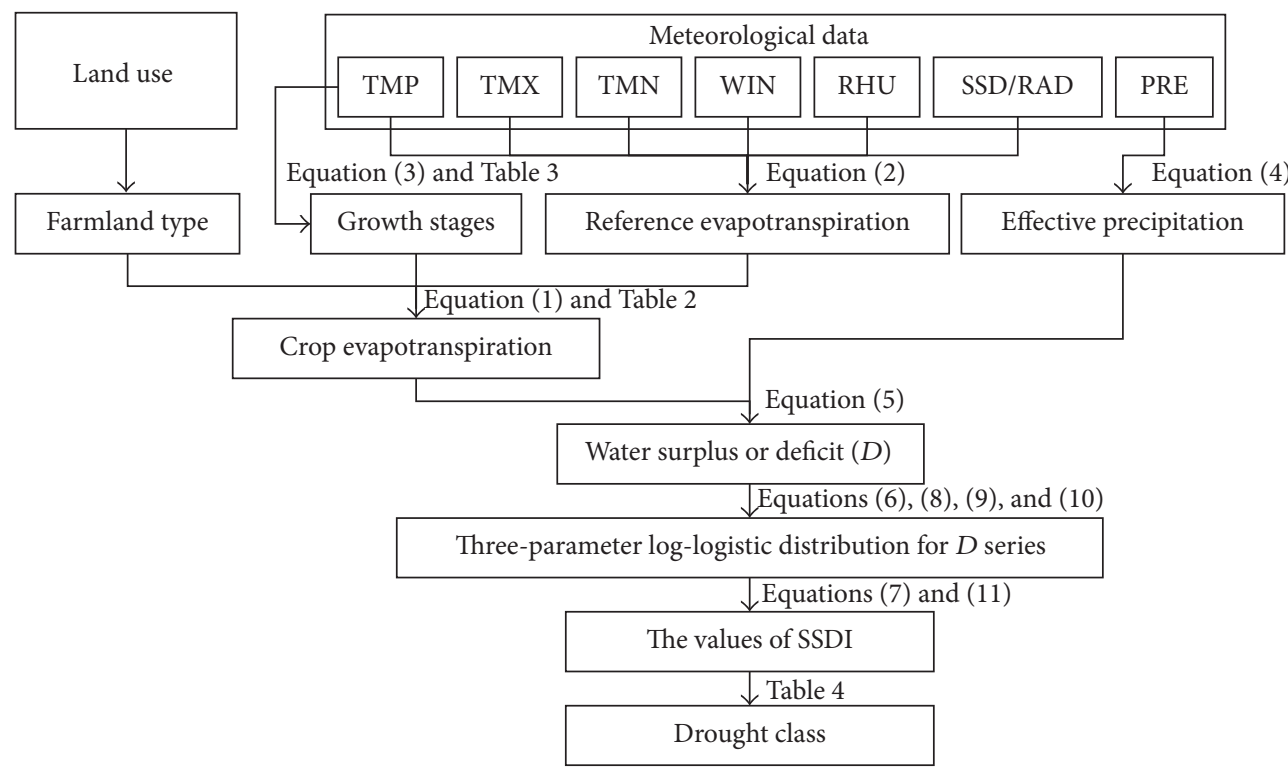

FIGURE 6: The procedure of drought assessment. TMP, TMX, TMN, WIN, RHU, SSD, RAD, and PRE are abbreviation for average temperature, highest temperature, lowest temperature, wind speed, relative humidity, sunshine hours, total solar radiation, and precipitation.

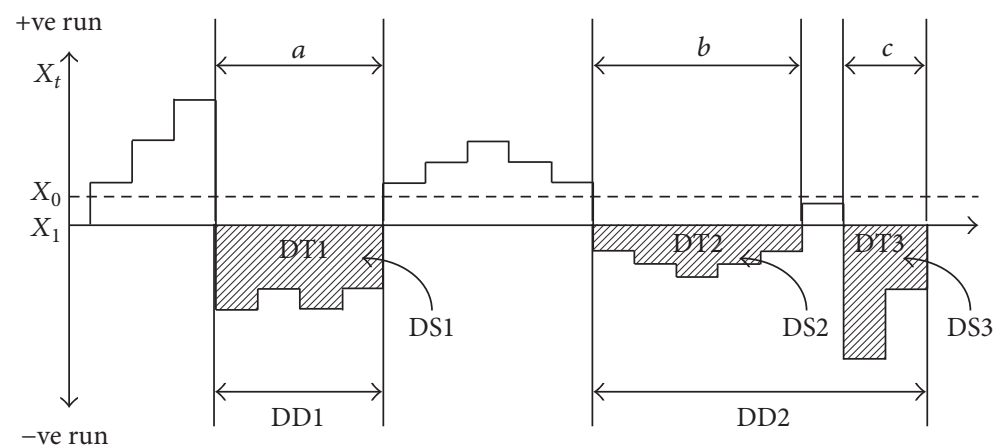

FIGURE 7: Drought characteristics using the run theory for a given threshold level.

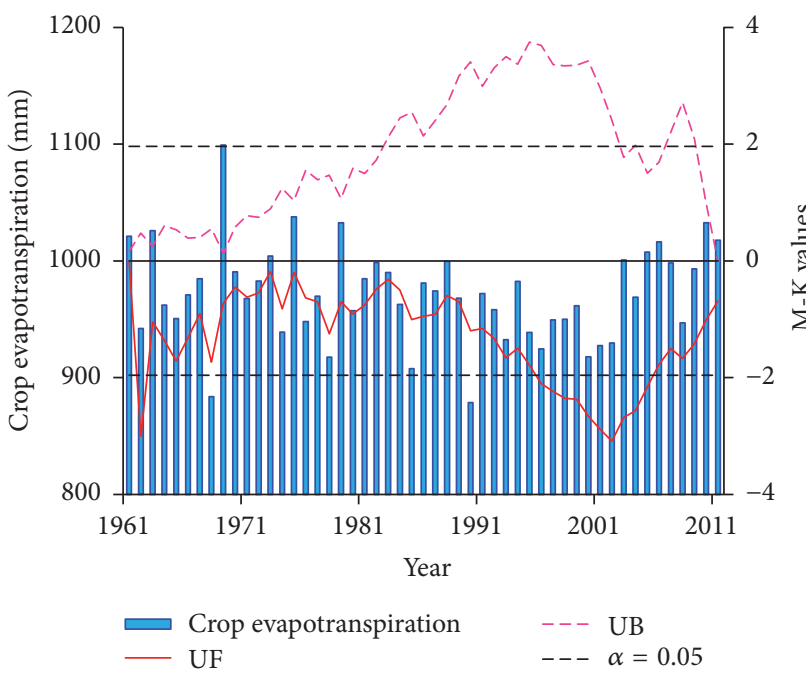

(a)

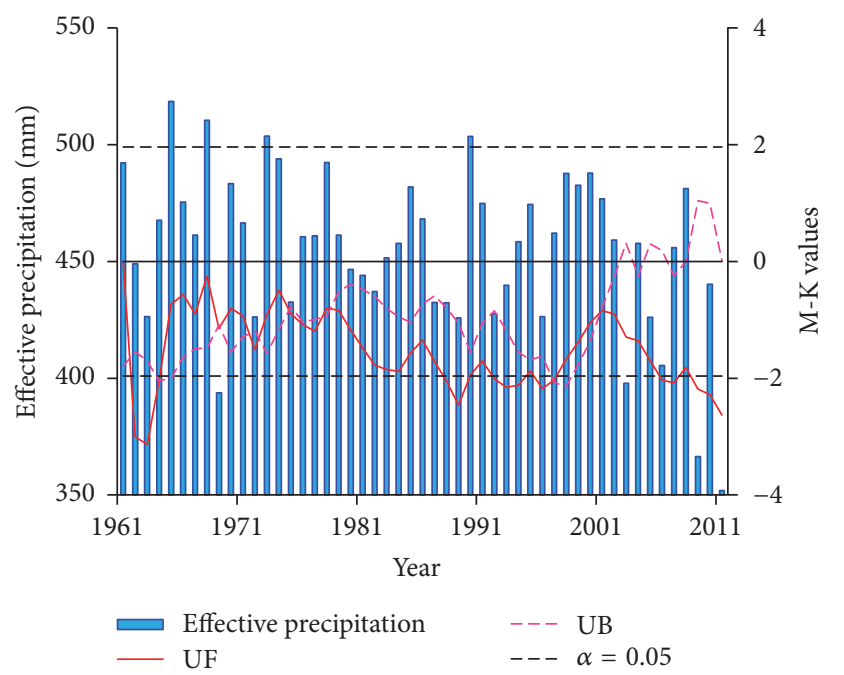

(b)

FIGURE 8: Crop evapotranspiration and effective precipitation during 1961 to 2011 and Mann-Kendall's testing statistical values: (a) areal crop evapotranspiration; (b) areal effective precipitation. 


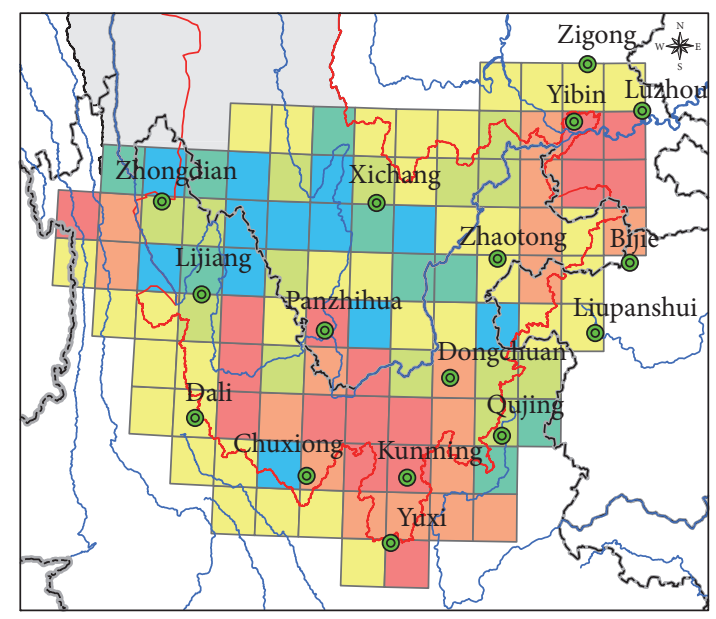

Slope of crop evapotranspiration from 1961 to 2011

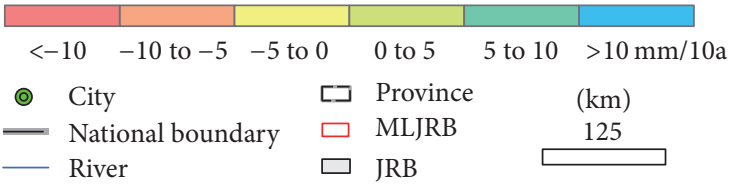

(a)

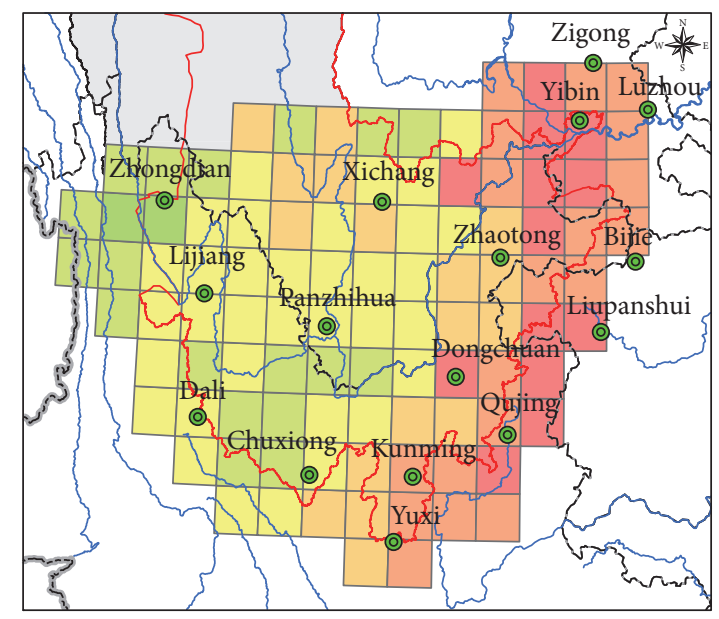

Slope of effective precipitation from 1961 to 2011

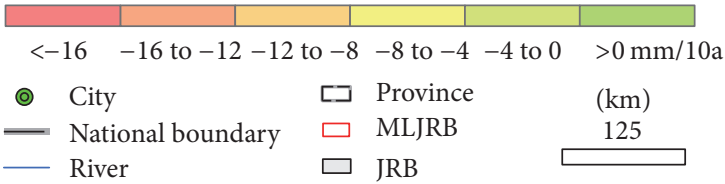

(b)

FIGURE 9: Distribution of slope for the period 1961 to 2011 across the MLJRB: (a) areal crop evapotranspiration; (b) areal effective precipitation.

3.2. Application of SSDI in the MLJRB during September 2009 to May 2010. From autumn in 2009 to spring in 2010, southwest China endured a severe drought episode. According to the China Drought \& Flood Climate Bulletin, the average rainfall during September 2009 to February 2010 in Yunnan Province was just $163.3 \mathrm{~mm}$, the lowest since 1952 [48]. The drought affected 200,000 ha of cash crops, with one-fifth of that without any harvest [49]. Given this, we applied the SSDI in MLJRB during September 2009 to May 2010 to verify the drought assessment method (Figure 10). It can be seen that the extreme drought struck in September, and it was distributed mainly in Xichang and Panzhihua, the north of the MLJRB. From October 2009 to February 2010, the extreme drought area traveled north-south- north, occurring in Chuxiong, Kunming, Yuxi, Yinbin, and Zhaotong. During this period, the extreme drought was mainly happened in the south of the MLJRB. After February 2010, the drought was gradually relieved. Overall, the spatial distribution of drought assessment was consistent with documented real drought.

In this study, we took Kunming city as an example to compare SSDI with SPI and SPEI (Figure 11). The results simulated by SSDI were partial consistency with SPI and SPEI. There exist some discrepancies in drought assessment. The drought category assessed by SSDI was slighter than SPI and SPEI in September. The reason of the disagreement was that the winter wheat was just sowed or has not yet been sowed during this period. Less water was required and the winter wheat was less sensitive to water deficit. However, the result simulated by SSDI was greater than SPI and SPEI in March. Mainly it was because the winter wheat had been undergoing a period of tillering-jointing. More water was required and the winter wheat was sensitive to water deficit.

\subsection{Spatial-Temporal Characteristics of Drought in MLJRB from 1961 to 2011}

3.3.1. Interannual Variability of Drought Area. The temporal variation of drought area was analyzed with SSDI12 (the time scale was 12 month) from 1961 to 2011 (Figure 12), which showed that the drought had obviously interannual and fluctuation in the MLJRB. The average drought area was $5.4 \times$ $10^{3} \mathrm{~km}^{2}$, accounting for $19.3 \%$ of the whole farmland area in the MLJRB. From the 1960s to the late 1990s, the drought exhibited a significant decreased trend. Compared with 1961 to 1990 , the drought area during 1991 to 2000 decreased by $76.0 \%$. But the drought area increased rapidly again after 2000. The drought area during 2001 to 2011 reached up to 9.9 $\times 10^{3} \mathrm{~km}^{2}$, which was about twice as the drought area before 2001 (Table 5).

3.3.2. Spatial Pattern of the Drought Characteristics. The values of DT, DD, and DS for each grid can demonstrate the spatial variance of drought characteristics. Figure 13 provides spatial comparison of the DT, DD, and DS of the drought characteristics from 1961 to 2011. It indicated that the grids with higher DT (>65 times) were mainly distributed in Yinbin, Zhaotong, Dali, Kunming, Chuxiong, and Yuxi (Figure 13(a)). These results imply that the northeast and south regions of the study area were prone to drought. Panzhihua, Xichang, and Chuxiong show higher drought durations, with total DD commonly reaching 125 month or more (Figure 13(b)). Panzhihua, Dali, Chuxiong, and Yuxi suffered from more severe drought. The absolute value of DS was more than 175 (Figure 13(c)). The results of the pattern for the DT, 

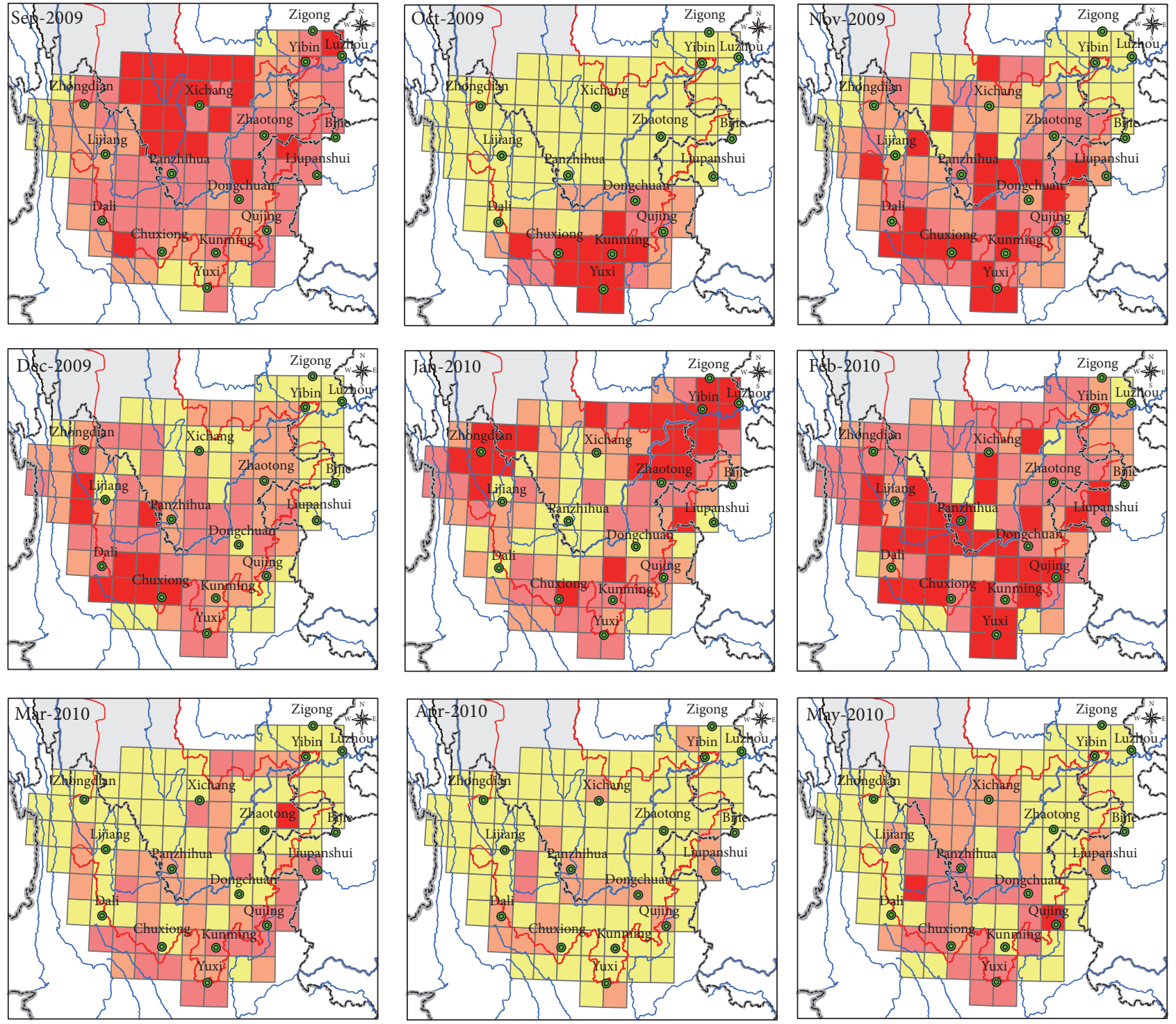

Drought category
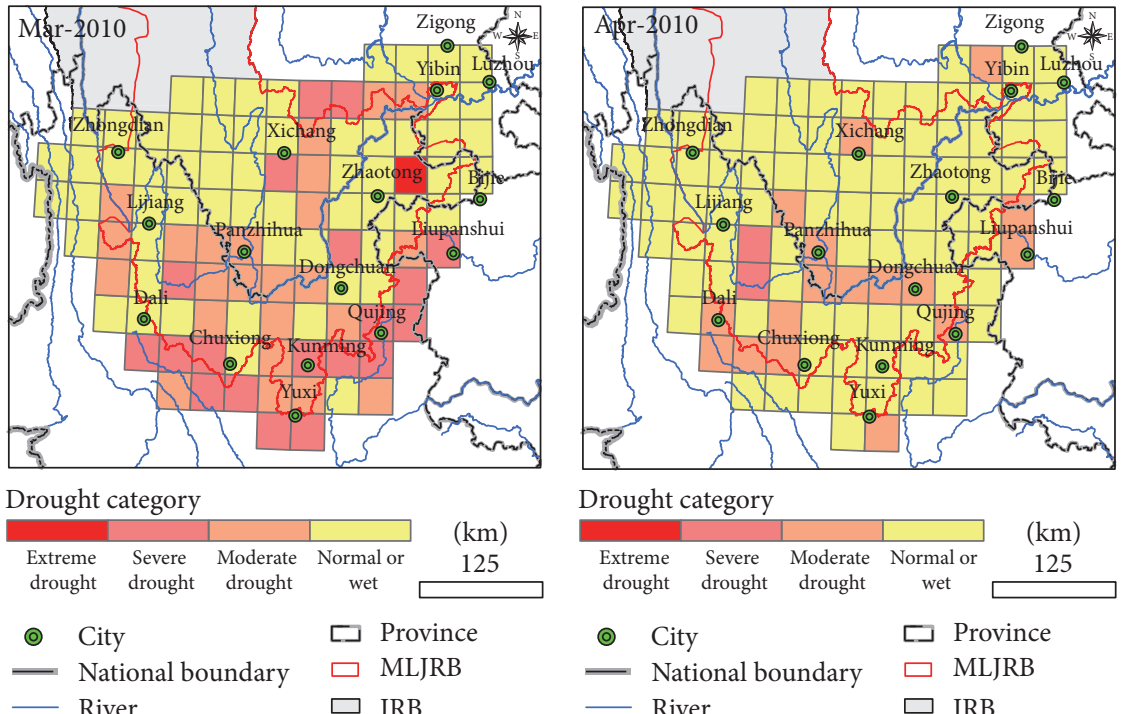

Drought category

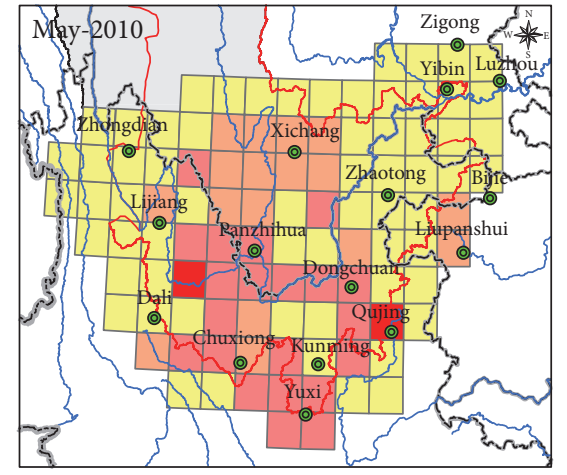

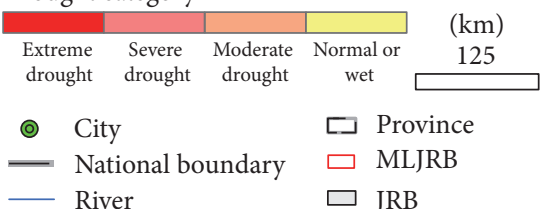

Drought category

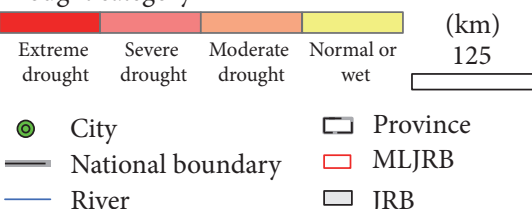

FIGURE 10: The distributed map of drought category from September 2009 to May 2010 based on modified SSDI.

TABLE 5: The multiyear average area of drought in the MLJRB (unit $10^{3} \mathrm{~km}^{2}$ ).

\begin{tabular}{lcccc}
\hline Period & $\begin{array}{c}\text { Moderate drought } \\
(-1.50<\text { SSDI } \\
\leq-1.00)\end{array}$ & $\begin{array}{c}\text { Severe drought } \\
(-2.00<\text { SSDI } \\
\leq-1.50)\end{array}$ & $\begin{array}{c}\text { Extreme drought } \\
(\text { SSDI } \leq 2.00)\end{array}$ & $\begin{array}{c}\text { Drought (SSDI } \\
\leq-1.00)\end{array}$ \\
\hline $1961-1970$ & 2.3 & 2.7 & 1.4 & 6.4 \\
$1971-1980$ & 2.4 & 1.9 & 0.2 & 4.5 \\
$1981-1990$ & 3.1 & 1.2 & 0.2 & 4.5 \\
$1991-2000$ & 1.3 & 0.0 & 0.1 & 1.5 \\
$2001-2011$ & 5.1 & 3.6 & 1.3 & 9.9 \\
\hline
\end{tabular}




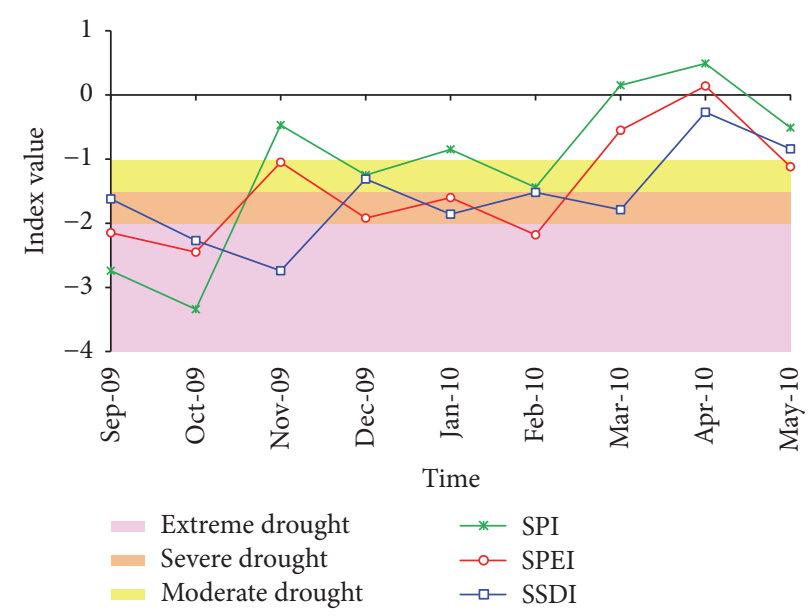

FIGURE 11: Compared SSDI with SPI and SPEI in Kunming city from September 2009 to May 2010.

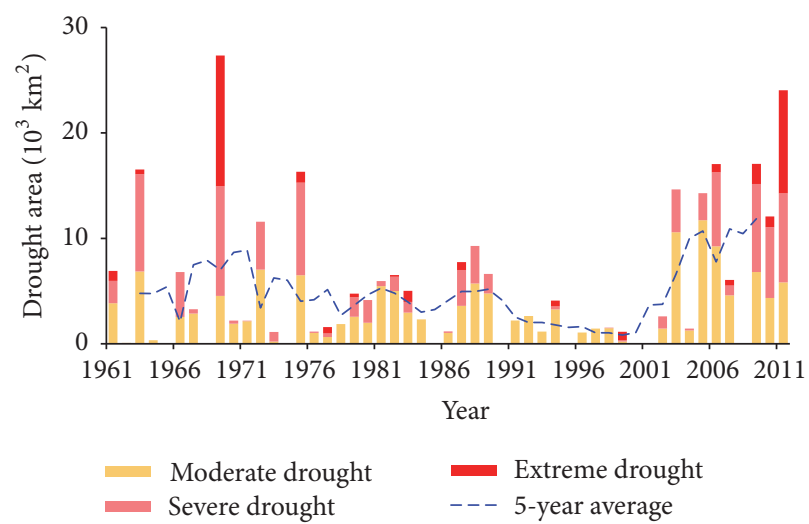

Figure 12: Annual variation of drought area from 1961 to 2011. In this study, the drought area means the area of farmland affected by drought.

$\mathrm{DD}$, and DS indicated that the grids for greater DS with more drought events and longer duration were mainly distributed in Dali, Chuxiong, Kunming, and Yuxi. These regions should cultivate drought-resistant crops and construct water saving irrigation project.

\subsection{Droughts under Future Climate Conditions}

3.4.1. Projected Changes in Crop Evapotranspiration and Effective Precipitation. As the crop evapotranspiration and effective precipitation determining the wet/dry state, we would firstly analyze spatial-temporal changes in crop evapotranspiration and effective precipitation for the reference period (1961 to 1990) to the projection period (2021 to 2050). Figure 14 shows the selection of relative optimal model for each grid's crop evapotranspiration and effective precipitation. We can find that HADGEM2-ES performed best of the five GCMs in this study, followed by IPSL-CM5A-LR and MIROC-ESM-CHEM.

Presented in Figure 15(a) is the geographic distribution of change in crop evapotranspiration, in terms of relative optimal model in the projection period (2020 to 2050) compared to the baseline period (1961-1990). The dominant feature in the projection period is an overall increase in crop evapotranspiration across the MLJRB. The crop evapotranspiration is predicted to increase by $7.6 \%$ for the period 2021-2050. There is a remarkable change of $15 \%$ compared to 1961-1990 climatology in Zhongdian, Lijiang, and Zhaotong. Future changes in effective precipitation, another important determinant of drought besides crop evapotranspiration, are highlighted in Figure 15(b). Widespread decreases in effective precipitation cover the whole region throughout the projection period. However, the change is not very noticeable. The effective precipitation is predicted to decrease by $3.0 \%$ for the period 2021-2050. There is a relatively pronounced decrease projected over northern parts of the MLJRB, such as Lijiang and Zhaotong.

\subsubsection{Projected Changes in Drought Characteristics}

(1) Drought Area. Using the crop evapotranspiration and effective precipitation of relative optimal models under RCP4.5 scenario, we carry out projections of annual drought area for the MLJRB. Figure 16 shows the change in drought 


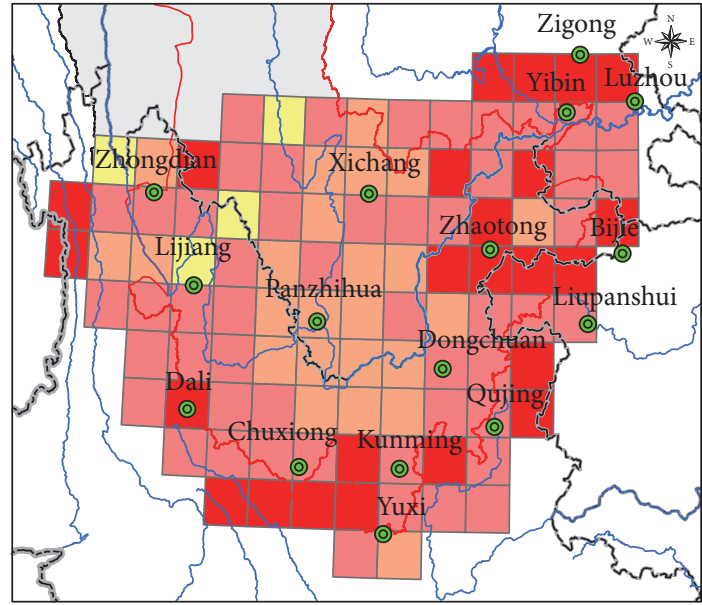

Drought times from 1961 to 2011

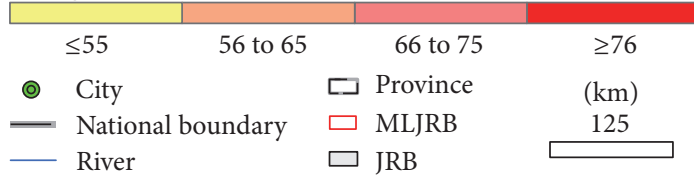

(a)

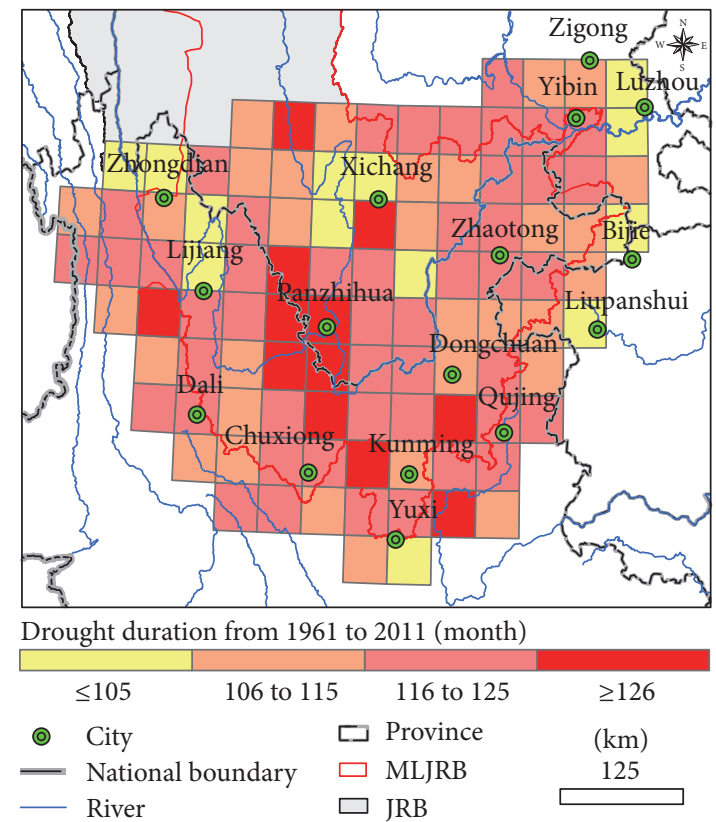

(b)

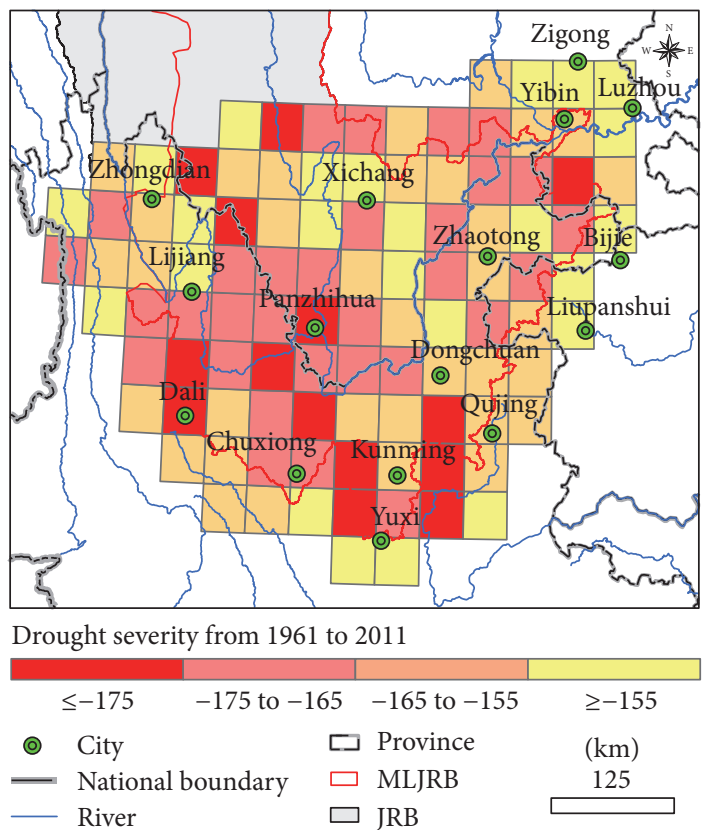

(c)

FIgURE 13: Spatial distribution of the DT (a), DD (b), and DS (c) in the MLJRB during 1961 to 2011.

area from 1961-1990 to 2021-2050. Compared with the average value for 1961-1990, the total area affected by drought $($ SSDI $\leq-1.5)$ for the period 2021-2050 will increase by about $43.2 \%$. It also can be seen that future changes in severe drought area $(-2.00<$ SSDI $\leq-1.50)$ have a marked increase trend. The change in severe drought area over the MLJRB is projected to increase by $70.1 \%$, far ahead of moderate drought area (increase by $28.5 \%$ ) and extreme drought area (increase by $50.1 \%)$.

(2) Drought Times, Duration, and Severity. The projection in drought characteristics, for example, drought times (DT), duration (DD), and severity (DS), is shown in Figure 17. There is a space consistency in increases or decreases in DT, DD, 


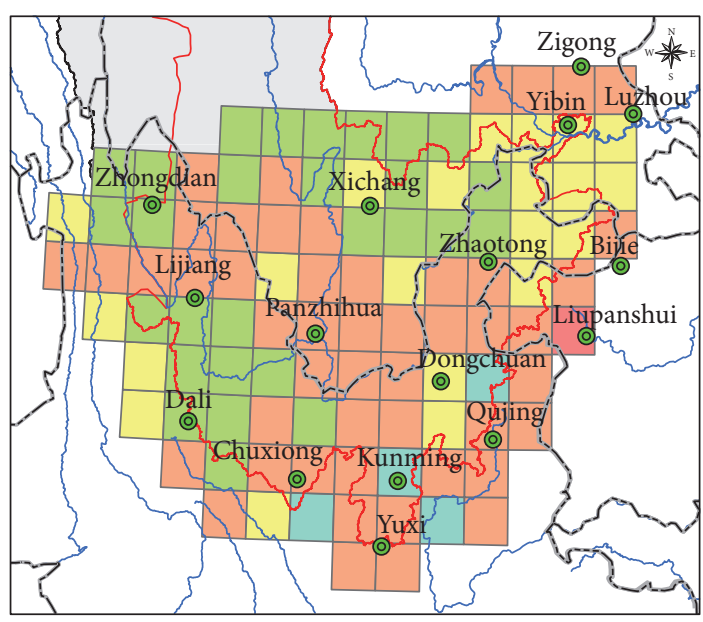

Relative optimal GCM for crop evapotranspiration simulation

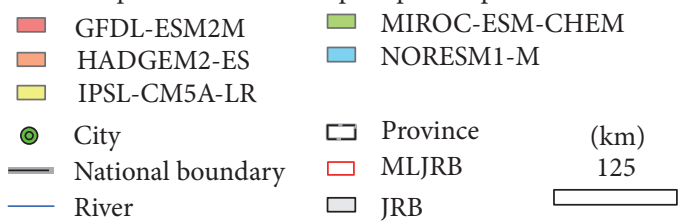

(a)

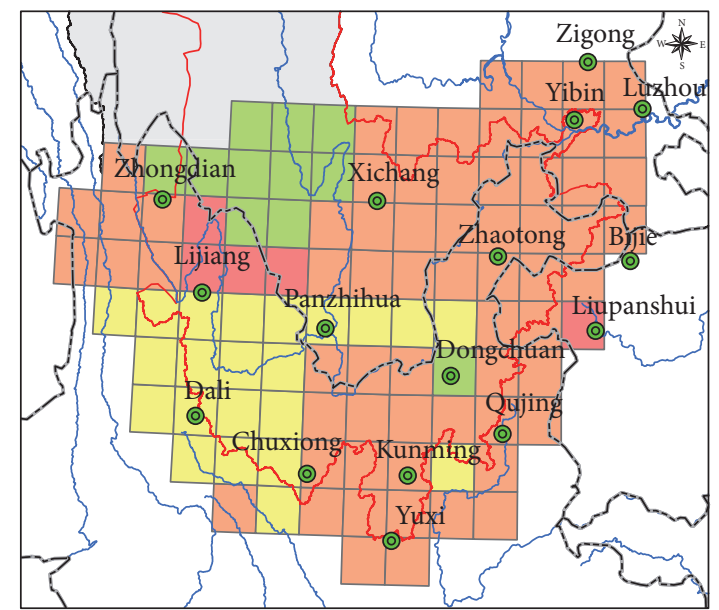

Relative optimal GCM for effective precipitation simulation

$$
\begin{aligned}
& \square \text { GFDL-ESM2M } \square \text { MIROC-ESM-CHEM } \\
& \square \text { HADGEM2-ES } \square \text { NORESM1-M } \\
& \square \quad \text { IPSL-CM5A-LR }
\end{aligned}
$$

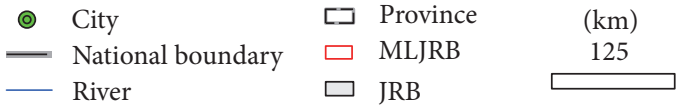

(b)

FIGURE 14: Spatial distribution of relative optimal climate models.

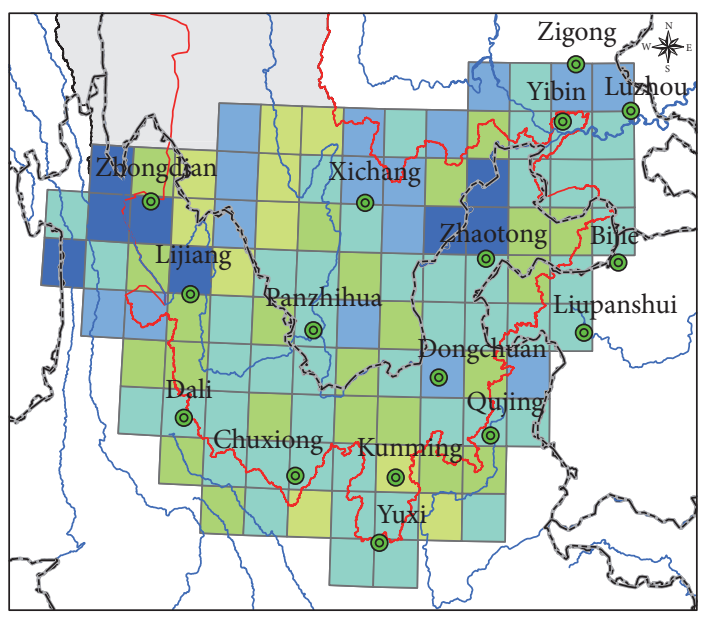

Relative change (\%) in average crop evapotranspiration

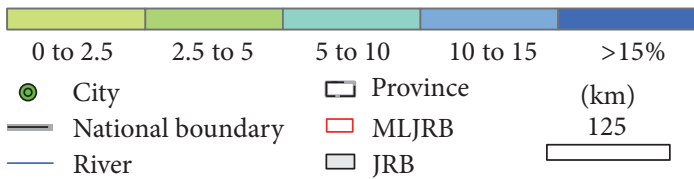

(a)

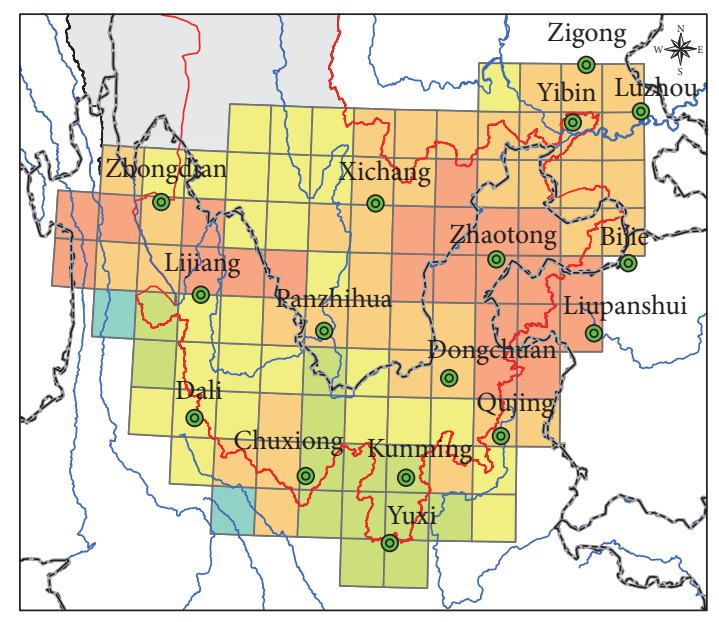

Relative change (\%) in average effective precipitation

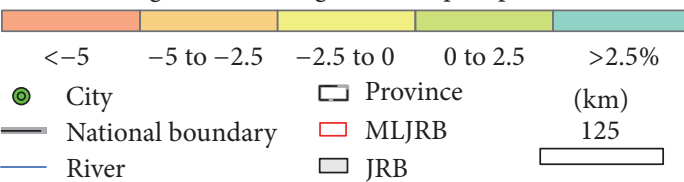

(b)

FIGURE 15: Spatial distribution of the percentage change in crop evapotranspiration and effective precipitation (\%) from the reference period (1961-1990) to 2021-2050. 


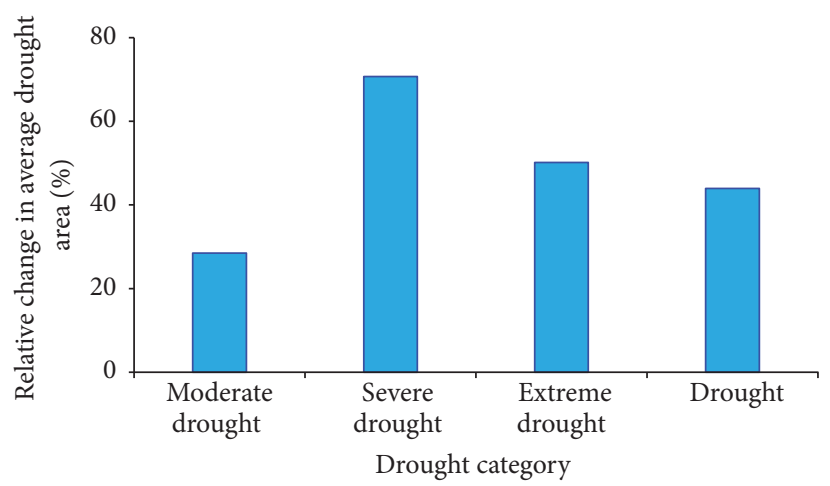

FIGURE 16: The percentage change in drought (\%) from the reference period (1961-1990) to 2021-2050.

and DS for the MLJRB during the period 2021 to 2050. The increase of DT, DD, and DS is mainly found in the north or west of the MLJRB. For large areas, such as Zhaotong, Lijiang, Panzhihua, and Dali, a relatively pronounced increase (more than 20\%) of DT, DD, and DS is projected, owing to the increase of crop evapotranspiration and decrease of effective precipitation. However, there are also some areas where decreased DT, DD, and DS are simulated, occurring in the southeast region, such as Kunming, Qujing, and Yuxi. It could be related to the less increase of crop evapotranspiration and relatively pronounced increase of effective precipitation. But under current climate conditions, more drought events and longer duration mainly occur in these regions compared with the north or west of the MLJRB. That is, the spatial pattern of the drought characteristics may change under future climate conditions. Perhaps, the drought-prone regions will shift from southeast to northwest in the MLJRB.

\section{Conclusions}

The variability and pattern of the drought characteristics are one of the most important aspects of drought disaster mitigation. Based on monthly or annual standardized supplydemand water index, in this study, we used drought area, times, duration, and severity as the main assessing indicators and investigated the spatial-temporal characteristics of drought in the middle and lower Jinsha river basin (MLJRB). Further, the projection of future drought conditions was estimated based on five GCMs and RCP4.5 scenario of greenhouse gas emission. The following conclusions are drawn from this study.

We have described a drought index (the standardized supply-demand water index (SSDI)) that uses crop evapotranspiration and effective precipitation and it is based on a normalization of the simple water balance. We applied this index in the MLJRB during September 2009 to May 2010, a severe drought episode in southwest China. The spatial distribution of drought assessment was consistent with documented real drought. We also assessed the properties and advantages of this index in comparison to the two most widely used drought indices: the standardized precipitation index (SPI) and the standardized precipitation evapotranspiration index (SPEI). The results showed that the SSDI can express the sensibility of crop to water deficit.

For the period 1961 to 2011, the average drought area was $5.4 \times 10^{3} \mathrm{~km}^{2}$, accounting for $19.3 \%$ of the whole farmland area in the MLJRB. During the last decade, the MLJRB has experienced widespread drought. The drought area during 2001 to 2011 reached up to $9.9 \times 10^{3} \mathrm{~km}^{2}$, which was about twice as the drought area during 1961 to 2000. The south of the MLJRB (e.g., Panzhihua, Chuxiong, Kunming, and Yuxi) is suffering from more severe drought, and the northeast region (e.g., Zhaotong and Yibin) with most drought events is prone to drought. The pattern for the drought characteristics indicated that the region for greater drought severity with more drought events and longer duration was mainly distributed in Dali, Chuxiong, Kunming, and Yuxi.

Under future climate condition, the crop evapotranspiration is projected to increase while the effective precipitation will change slightly. That is, the water deficit will exacerbate in the future. This climate change further intensifies drought conditions in the MLJRB. For the period 2021 to 2050, an increase of total drought area by $43.2 \%$ was simulated. The projection also gives an increase of severe drought area by $70.1 \%$. Compared to the reference period (1961-1990), the MLJRB is likely to experience more widespread drought in the future. The increase of drought times, duration, and severity is mainly found in the north or west of the MLJRB, especially in Zhaotong, Lijiang, Panzhihua, and Dali. We can conclude that the spatial pattern of the drought characteristics may change under future climate conditions. Perhaps, the drought-prone regions could move further towards the northwest of the MLJRB.

The proposed drought assessment methodology will provide a tool for water managers to analyze the impacts of climate change on drought conditions. For the development of a long-term regional water plan and the preparedness for drought, information regarding future drought conditions is valuable. So, the conclusions can also help decision-makers 


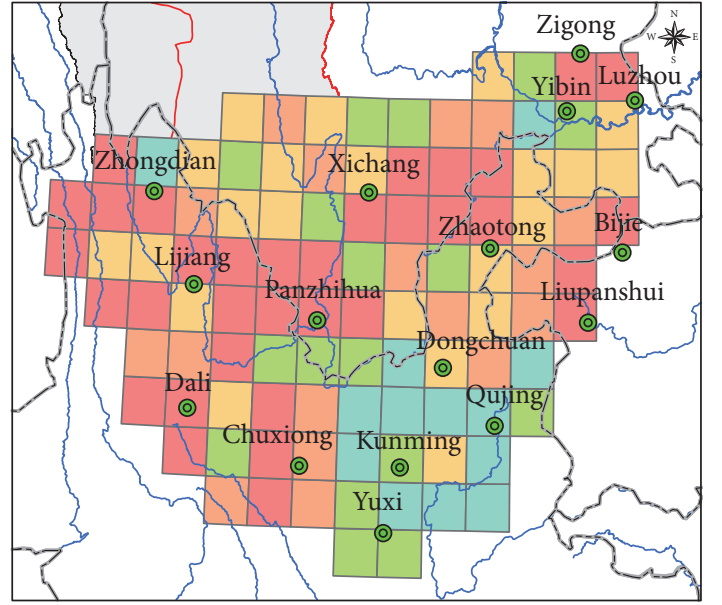

Relative change (\%) in drought times

\begin{tabular}{llll}
\hline$<-10 \quad-10$ to 0 & 0 to $10 \quad 10$ to 20 & $>20 \%$ \\
○) City & $\square$ Province & $(\mathrm{km})$ \\
\hline $\begin{array}{l}\text { National boundary } \\
\text { River }\end{array}$ & $\square$ MLJRB & 125 \\
\hline
\end{tabular}

(a)

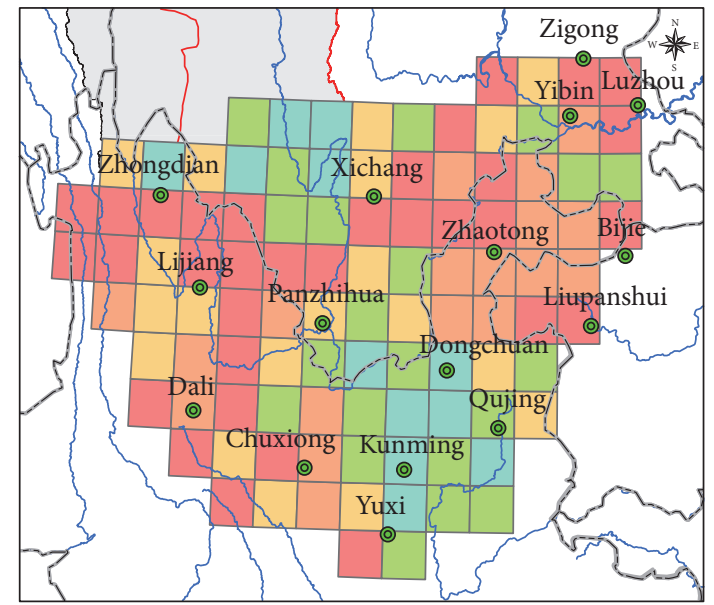

Relative change (\%) in drought duration

\begin{tabular}{llll}
\hline$<-10 \quad-10$ to 0 & 0 to $10 \quad 10$ to 20 & $>20 \%$ \\
& $\square$ Province & $(\mathrm{km})$ \\
○ City & $\square$ MLJRB & 125 \\
\hline $\begin{array}{l}\text { National boundary } \\
\text { N }\end{array}$ & $\square$ Miver
\end{tabular}

(b)

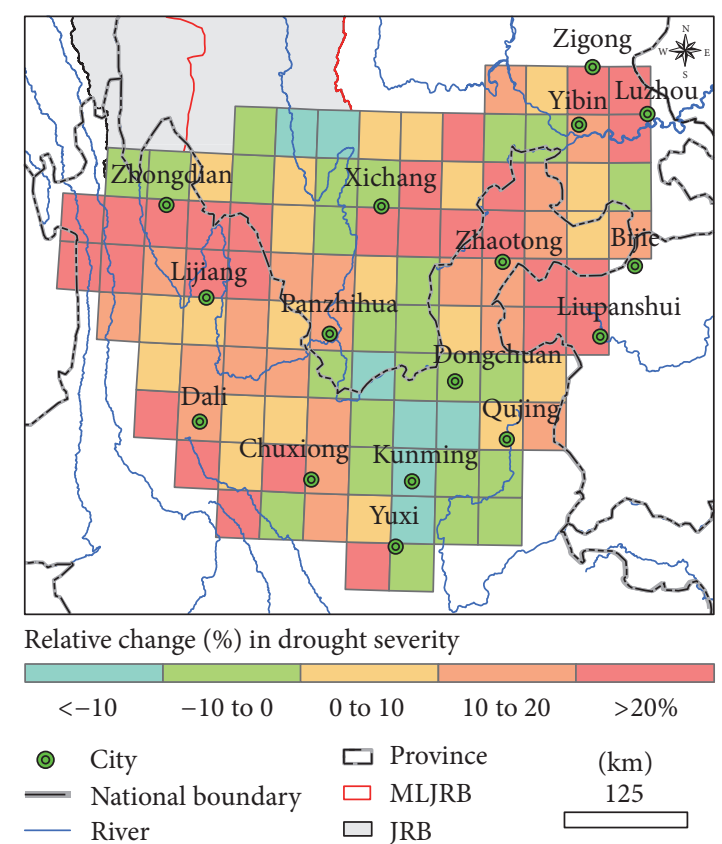

(c)

Figure 17: Spatial distribution of the percentage change in drought times (a), duration (b), and severity (c) (\%) from the reference period (1961-1990) to 2021-2050.

to establish management of drought mitigation strategies on a regional scale.

\section{Conflicts of Interest}

The authors declare that they have no conflicts of interest.

\section{Acknowledgments}

This research was financially supported by International Science \& Technology Cooperation Program of China "Integrated Risk Management of Water Resources for Adaptation to Climate Change in Jinsha River Basin" (no. 2014DFA71910); National Public Research Institutes for Basic 
R\&D Operating Expenses Special Project (no. CKSF2017029 and no. CKSF2017061/SZ); National Key Research and Development Project (no. 2016YFC0402707); China Clean Development Mechanism Fund (no. 2014110); National Natural Science Foundation of China (no. 51609009 and no. 41601043); Major Competitive Project of Hydraulic Science and Technology (KT201514).

\section{References}

[1] S.-K. Min, X. Zhang, F. W. Zwiers, and G. C. Hegerl, "Human contribution to more-intense precipitation extremes," Nature, vol. 470, no. 7334, pp. 378-381, 2011.

[2] A. Dai, K. E. Trenberth, and T. Qian, "A global dataset of Palmer Drought Severity Index for 1870-2002: relationship with soil moisture and effects of surface warming," Journal of Hydrometeorology, vol. 5, no. 6, pp. 1117-1130, 2004.

[3] United Nations International Strategy for Disaster Reduction Secretariat United Nations International Strategy for Disaster Reduction Secretariat, New York, NY, USA, 2009.

[4] D. Qin, Y. Ding, J. Su et al., "Assessment of climate and environment changes in China (I): climate and environment changes in China and their projection," Advances in Climate Change Research, vol. 2, pp. 1-5, 2006 (Chinese).

[5] Y. Wu and H. Gao, "The relief records of severe drought disasters since the founding of P. R. China," China Flood and Drought Management, vol. 19, no. 1, pp. 39-65, 2009 (Chinese).

[6] J. Peng, Q. Zhang, and C. Bueh, "On the characteristics and possible causes of a severe drought and heat wave in the Sichuan-Chongqing region in 2006," Climatic and Environmental Research, vol. 12, no. 3, pp. 464-474, 2007 (Chinese).

[7] R. H. Huang, Y. Liu, L. Wang et al., "Analyses of the causes of severe drought occurring in Southwest China from the fall of 2009 to the spring of 2010," Chinese Journal of Atmospheric Sciences, vol. 36, no. 3, pp. 443-457, 2012 (Chinese).

[8] E. Lu, Y. L. Luo, R. H. Zhang, Q. Wu, and L. Liu, "Regional atmospheric anomalies responsible for the 2009-2010 severe drought in China," Journal of Geophysical Research D: Atmospheres, vol. 116, no. 21, Article ID D21114, 2011.

[9] A. K. Mishra and V. P. Singh, "A review of drought concepts," Journal of Hydrology, vol. 391, no. 1-2, pp. 202-216, 2010.

[10] B. He, A. Lü, J. Wu, L. Zhao, and M. Liu, "Drought hazard assessment and spatial characteristics analysis in China," Journal of Geographical Sciences, vol. 21, no. 2, pp. 235-249, 2011.

[11] W. C. Palmer, "Meteorological drought," Research Paper 45, United States Department of Commerce, Weather Bureau, Washington, DC, USA, 1965.

[12] T. B. McKee, N. J. Doesken, and J. Kleist, "The relationship of drought frequency and duration to time scales," in Proceedings of the 8th Conference on Applied Climatology, pp. 179-184, 1993.

[13] L. Wang and W. Chen, "Applicability analysis of Standardized Precipitation Evapotranspiration Index in drought monitoring in China," Plateau Meteorol, vol. 33, no. 2, pp. 423-431, 2014 (Chinese).

[14] IPCC, Climate Change 2007: The Physical Science Basis, Cambridge University Press, Cambridge, UK, 2007.

[15] IPCC, Climate Change 2013: The Physical Science Basis, Cambridge University Press, Cambridge, UK, 2013.

[16] S. M. Vicente-Serrano, S. Beguería, and J. I. López-Moreno, "A multiscalar drought index sensitive to global warming: the standardized precipitation evapotranspiration index," Journal of Climate, vol. 23, no. 7, pp. 1696-1718, 2010.
[17] M. X. Yu, Q. F. Li, M. J. Hayes, M. D. Svoboda, and R. R. Heim, "Are droughts becoming more frequent or severe in China based on the standardized precipitation evapotranspiration index: 1951-2010?" International Journal of Climatology, vol. 34, no. 3, pp. 545-558, 2014.

[18] G. Tsakiris, D. Pangalou, and H. Vangelis, "Regional drought assessment based on the reconnaissance drought index (RDI)," Water Resources Management, vol. 21, no. 5, pp. 821-833, 2007.

[19] J. Zhai, J. Huang, B. Su et al., "Intensity-area-duration analysis of droughts in China 1960-2013," Climate Dynamics, vol. 48, no. 1-2, pp. 151-168, 2016.

[20] Z. Yuan, Z. Yang, D. Yan et al., "Historical changes and future projection of extreme precipitation in China," Theoretical and Applied Climatology, vol. 127, no. 1, pp. 393-407, 2017.

[21] S. J. Wang, X. L. Zhang, Z. G. Liu, and D. M. Wang, "Trend analysis of precipitation in the Jinsha River Basin in China," Journal of Hydrometeorology, vol. 14, no. 1, pp. 290-303, 2013.

[22] H. Liu, H. Lan, Y. Liu, and Y. Zhou, "Characteristics of spatial distribution of debris flow and the effect of their sediment yield in main downstream of Jinsha River, China," Environmental Earth Sciences, vol. 64, no. 6, pp. 1653-1666, 2011.

[23] S. Wang and X. Zhang, "Long-term trend analysis for temperature in the Jinsha River Basin in China," Theoretical and Applied Climatology, vol. 109, no. 3-4, pp. 591-603, 2012.

[24] Y. Chen, W. Wang, G. Wang et al., "Characteristics analysis on temperature and precipitation variation in Jinsha River Basin," Plateau and Mountain Meteorology Research, vol. 30, no. 40, pp. 51-56, 2010 (Chinese).

[25] J. Du and C. Shi, "Modeling and analysis of effects of precipitation and vegetation coverage on runoff and sediment yield in Jinsha River Basin," Water Science and Engineering, vol. 6, no. 1, pp. 44-58, 2013.

[26] Q. Zhang, "The South-to-North Water Transfer Project of China: environmental implications and monitoring strategy," Journal of the American Water Resources Association, vol. 45, no. 5, pp. 1238-1247, 2009.

[27] W. Wang, W. Wang, J. Li et al., "The impact of sustained drought on vegetation ecosystem in Southwest China based on remote sensing," Procedia Environmental Sciences, vol. 2, pp. 1679-1691, 2010.

[28] L. Zhang, J. F. Xiao, J. Li, K. Wang, L. Lei, and H. Guo, “The 2010 spring drought reduced primary productivity in southwestern China," Environmental Research Letters, vol. 7, no. 4, Article ID 045706, 2012.

[29] M. J. Zhang, J. Y. He, B. L. Wang et al., "Extreme drought changes in Southwest China from 1960 to 2009," Journal of Geographical Sciences, vol. 23, no. 1, pp. 3-16, 2013.

[30] M. F. Hutchinson, "Interpolation of rainfall data with thin plate smoothing splines. Part I: two dimensional smoothing of data with short range correlation," Journal of Geographic Information and Decision Analysis, vol. 2, no. 2, pp. 139-151, 1998.

[31] M. F. Hutchinson, "Interpolation of rainfall data with thin plate smoothing splines. Part II: analysis of topographic dependence," Journal of Geographic Information and Decision Analysis, vol. 2, no. 2, pp. 152-167, 1998.

[32] X. Gao, J. Xu, S. Yang et al., "Water requirement pattern and crop coefficient of main crops in Guizhou province," China Rural Water and Hydropower, vol. 1, pp. 11-17, 2015 (Chinese).

[33] Q. Lu and L. Wang, "China main varieties of rice and wheat cotton growing season accumulated temperature," Acta Agronomica Sinica, vol. 4, no. 2, pp. 157-169, 1965 (Chinese). 
[34] Y. Gao, The Influence of the Climate Change on Irrigation Water Demand of Heihe River Basins Typical Crops and Its Synthetical Measures, Chinese, Donghua University, 2013.

[35] L. Warszawski, K. Frieler, V. Huber, F. Piontek, O. Serdeczny, and J. Schewe, "The inter-sectoral impact model intercomparison project (ISI-MIP): project framework," Proceedings of the National Academy of Sciences of the United States of America, vol. 111, no. 9, pp. 3228-3232, 2014.

[36] C. Piani, G. P. Weedon, M. Best et al., "Statistical bias correction of global simulated daily precipitation and temperature for the application of hydrological models," Journal of Hydrology, vol. 395, no. 3-4, pp. 199-215, 2010.

[37] S. Hagemann, C. Chen, J. O. Haerter, J. Heinke, D. Gerten, and C. Piani, "Impact of a statistical bias correction on the projected hydrological changes obtained from three GCMs and two hydrology models," Journal of Hydrometeorology, vol. 12, no. 4, pp. 556-578, 2011.

[38] R. G. Allen, A. J. Clemmens, C. M. Burt, K. Solomon, and T. O'Halloran, "Prediction accuracy for projectwide evapotranspiration using crop coefficients and reference evapotranspiration," Journal of Irrigation and Drainage Engineering, vol. 131, no. 1, pp. 24-36, 2005.

[39] E. E. Maeda, P. K. E. Pellikka, B. J. F. Clark, and M. Siljander, "Prospective changes in irrigation water requirements caused by agricultural expansion and climate changes in the eastern arc mountains of Kenya," Journal of Environmental Management, vol. 92, no. 3, pp. 982-993, 2011.

[40] Y. Shen, S. Li, Y. Chen, Y. Qi, and S. Zhang, "Estimation of regional irrigation water requirement and water supply risk in the arid region of Northwestern China 1989-2010," Agricultural Water Management, vol. 128, pp. 55-64, 2013.

[41] Z. Yuan, D. Yan, Z. Yang, J. Yin, P. Breach, and D. Wang, "Impacts of climate change on winter wheat water requirement in Haihe River Basin," Mitigation and Adaptation Strategies for Global Change, vol. 21, no. 5, pp. 677-697, 2016.

[42] M. Smith, CROPWAT: A Computer Program for Irrigation Planning and Management, Food and Agriculture Organization, Rome, Italy, 1992.

[43] M. I. Ahmad, C. D. Sinclair, and A. Werritty, "Log-logistic flood frequency analysis," Journal of Hydrology, vol. 98, no. 3-4, pp. 205-224, 1988.

[44] J. R. M. Hosking, "L-moments: analysis and estimation of distributions using linear combinations of order statistics," Journal of the Royal Statistical Society B: Methodological, vol. 52, no. 1, pp. 105-124, 1990.

[45] L. Vermes, Source: How to Work out a Drought Mitigation Strategy; An ICID Guide. Guidelines for Water Management vol. 309, Wirtschafts- und Verlagsgesellschaft Gas und Wasser, 1998.

[46] L. A. Moyé, A. S. Kapadia, I. M. Cech, and R. J. Hardy, "The theory of runs with applications to drought prediction," Journal of Hydrology, vol. 103, no. 1-2, pp. 127-137, 1988.

[47] G. Lu, G. Yan, Z. Wu et al., "Regional drought analysis approach based on copula function," Advances in Water Science, vol. 21, pp. 188-193, 2010 (Chinese).

[48] China National Climate Center, China Drought \& Flood Climate Bulletin, 2010 (Chinese).

[49] T. Ye, P. Shi, J. Wang, L. Liu, Y. Fan, and J. Hu, "China’s drought disaster risk management: perspective of severe droughts in 2009-2010," International Journal of Disaster Risk Science, vol. 3, no. 2, pp. 84-97, 2012. 

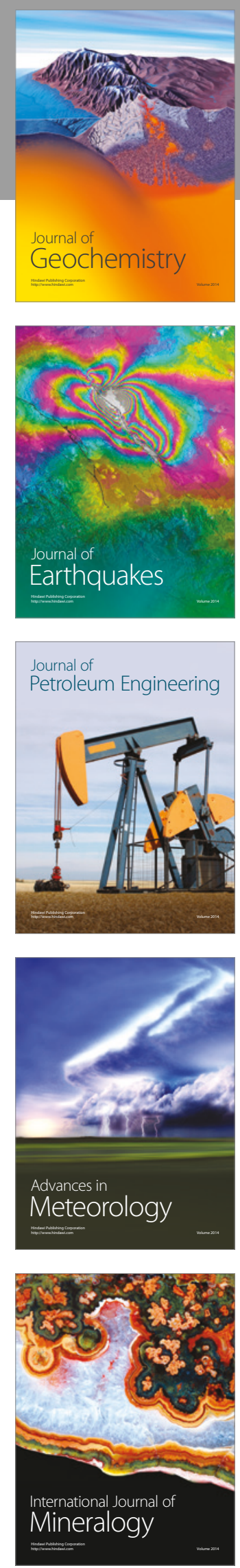
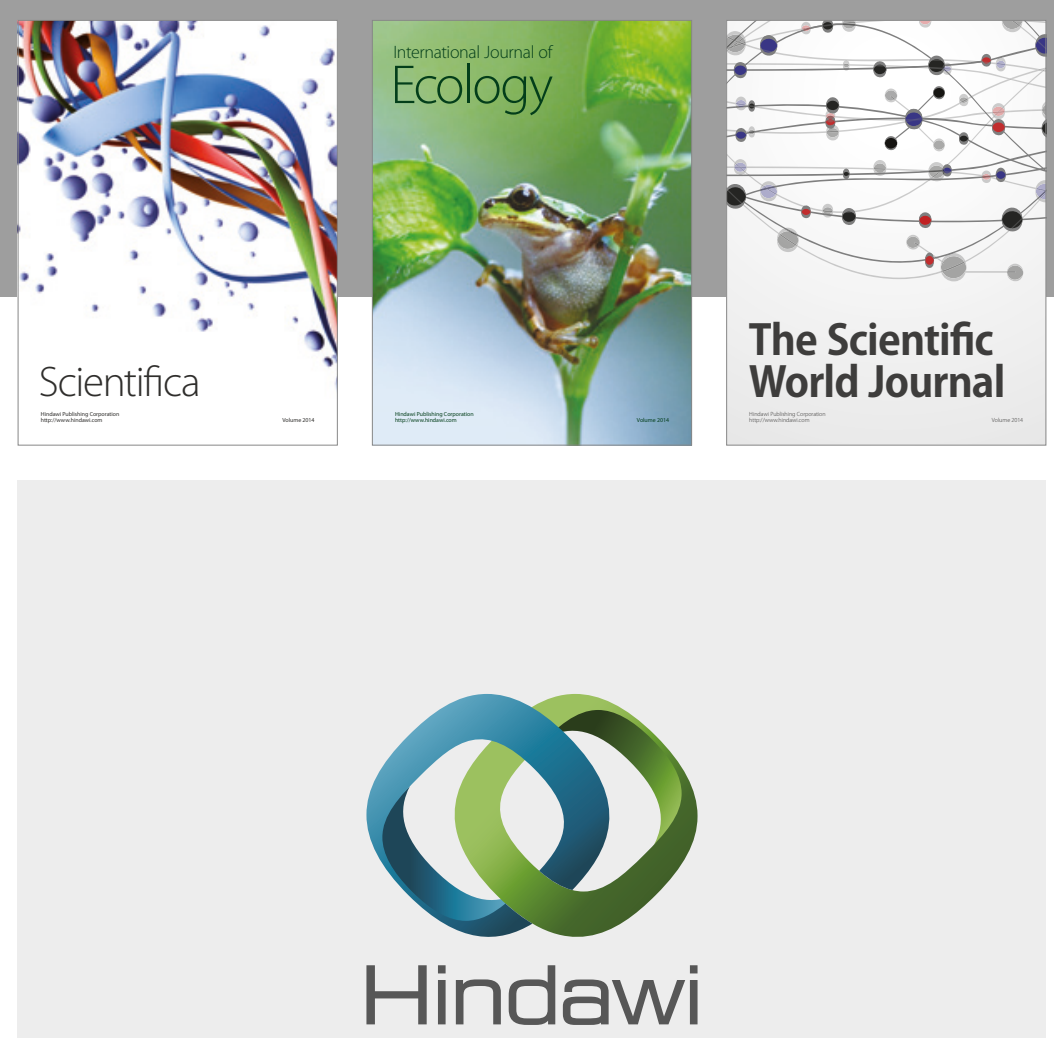

Submit your manuscripts at

https://www.hindawi.com
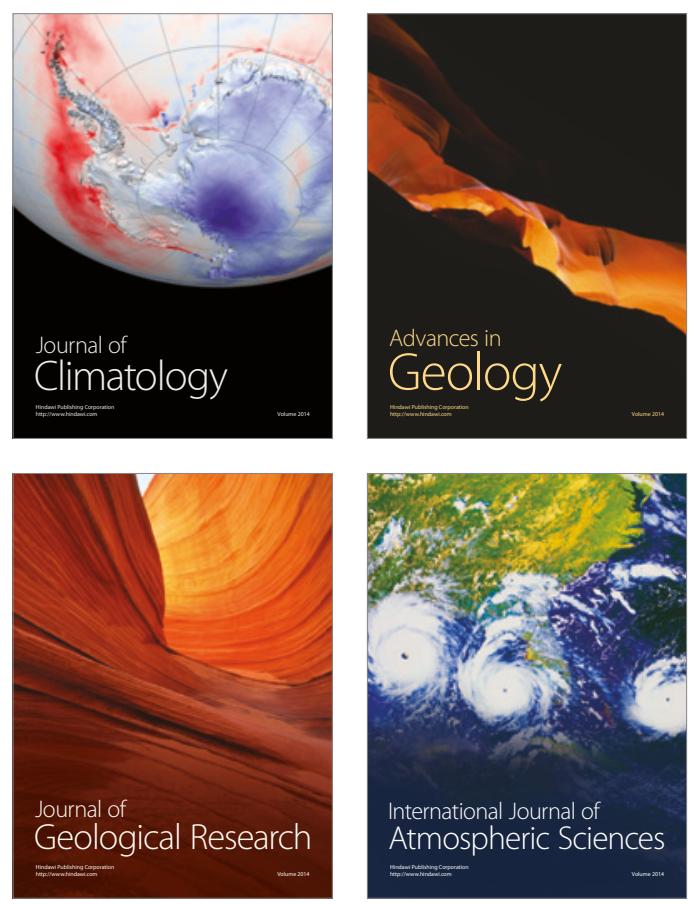

The Scientific

World Journal
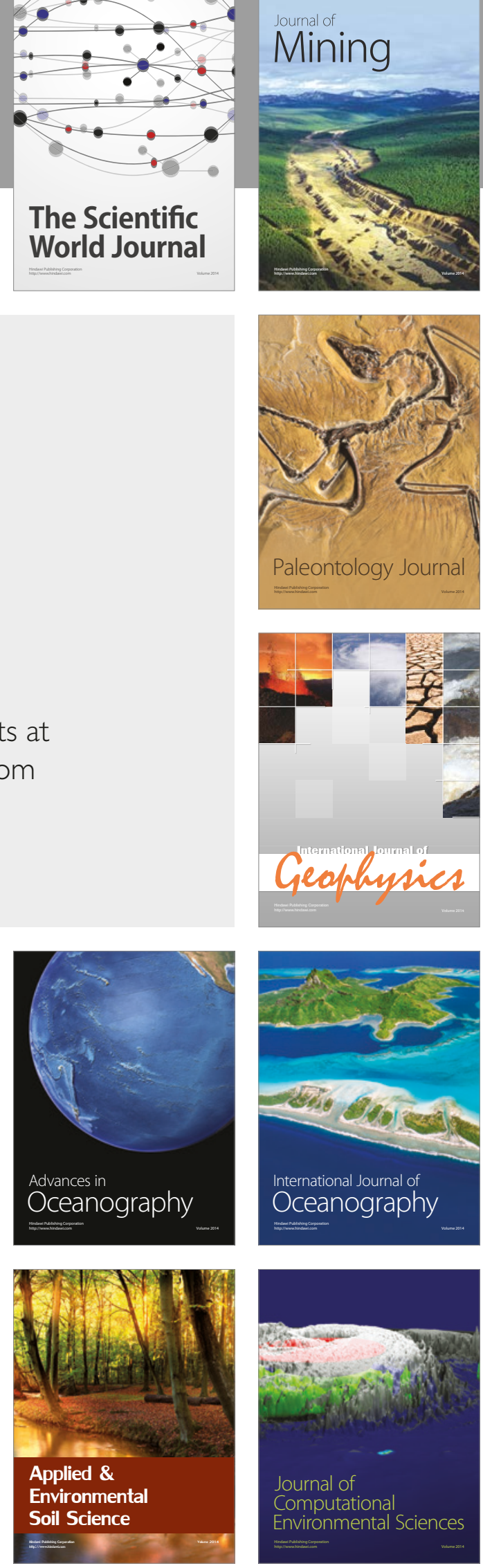